\title{
Cardiovascular and Cerebrovascular Disease Associated microRNAs Are Dysregulated in Placental Tissues Affected with Gestational Hypertension, Preeclampsia and Intrauterine Growth Restriction
}

\author{
Ilona Hromadnikova ${ }^{1}$, Katerina Kotlabova ${ }^{1}$, Lucie Hympanova ${ }^{1,2}$, Ladislav Krofta $^{2}$ \\ 1 Department of Molecular Biology and Cell Pathology, Third Faculty of Medicine, Charles University, \\ Prague, Czech Republic, 2 Institute for the Care of the Mother and Child, Third Faculty of Medicine, Charles \\ University, Prague, Czech Republic \\ * Ilona.Hromadnikova@lf3.cuni.cz
}

\section{Abstract}

\section{G openaccess}

Citation: Hromadnikova I, Kotlabova K, Hympanova L, Krofta L (2015) Cardiovascular and Cerebrovascular Disease Associated microRNAs Are Dysregulated in Placental Tissues Affected with Gestational Hypertension, Preeclampsia and Intrauterine Growth Restriction. PLOS ONE 10(9): e0138383. doi:10.1371/journal.pone. 0138383

Editor: Kandiah Jeyaseelan, National University of Singapore, SINGAPORE

Received: May 26, 2015

Accepted: August 28, 2015

Published: September 22, 2015

Copyright: $\odot 2015$ Hromadnikova et al. This is an open access article distributed under the terms of the Creative Commons Attribution License, which permits unrestricted use, distribution, and reproduction in any medium, provided the original author and source are credited.

Data Availability Statement: All relevant data are within the paper.

Funding: The work was exclusively supported by the Charles University research program PRVOUK P32.

Competing Interests: The authors have declared that no competing interests exist.

\section{Aims}

To demonstrate that pregnancy-related complications are associated with alterations in cardiovascular and cerebrovascular microRNA expression. Gene expression of 32 microRNAs (miR-1-3p, miR-16-5p, miR-17-5p, miR-20a-5p, miR-20b-5p, miR-21-5p, miR-23a-3p, miR-24-3p, miR-26a-5p, miR-29a-3p, miR-33a-5p, miR-92a-3p, miR-100-5p, miR-103a-3p, miR-122-5p, miR-125b-5p, miR-126-3p, miR-130b-3p, miR-133a-3p, miR-143-3p, miR145-5p, miR-146a-5p, miR-155-5p, miR-181a-5p, miR-195-5p, miR-199a-5p, miR-208a-3p, miR-210-3p, miR-221-3p, miR-342-3p, miR-499a-5p, and miR-574-3p) was assessed in placental tissues, compared between groups (35 gestational hypertension, 80 preeclampsia, 35 intrauterine growth restriction and 20 normal pregnancies) and correlated with the severity of the disease with respect to clinical signs, delivery date, and Doppler ultrasound parameters. Initially, selection and validation of endogenous controls for microRNA expression studies in placental tissues affected by pregnancy-related complications have been carried out.

\section{Results}

The expression profile of microRNAs was different between pregnancy-related complications and controls. The up-regulation of miR-499a-5p was a common phenomenon shared between gestational hypertension, preeclampsia, and intrauterine growth restriction. Preeclamptic pregnancies delivering after 34 weeks of gestation and IUGR with abnormal values of flow rate in the umbilical artery demonstrated up-regulation of miR-1-3b. Preeclampsia and IUGR requiring termination of gestation before 34 weeks of gestation were associated with down-regulation of miR-26a-5p, miR-103a-3p and miR-145-5p. On the 
other hand, some of microRNAs (miR-16-5p, miR-100-5p, miR-122-5p, miR-125b-5p, miR126-3p, miR-143-3p, miR-195-5p, miR-199a-5p, miR-221-3p, miR-342-3p, and miR-574$3 p)$ were only down-regulated or showed a trend to down-regulation just in intrauterine growth restriction pregnancies requiring the delivery before 34 weeks of gestation.

\section{Conclusion}

Epigenetic changes induced by pregnancy-related complications in placental tissue may cause later onset of cardiovascular and cerebrovascular diseases in offspring.

\section{Introduction}

Preeclampsia and fetal growth restriction (FGR) are major complications affecting 2-10\% of pregnancies responsible for maternal and perinatal morbidity and mortality [1,2]. Preeclampsia usually develops after 20 weeks of gestation and is characterized by chronic or gestational hypertension combined with proteinuria [3], which results from defective placentation eliciting inadequate uteroplacental blood perfusion and ischemia $[4,5]$. The causes of preeclampsia and FGR remain unknown; however, preeclampsia is thought to be an implantation disorder [6].

Hypertension in pregnancy induces long-term metabolic and vascular abnormalities that might increase the overall risk of cardiovascular, cerebrovascular, and kidney diseases, as well as diabetes mellitus, later in life [7-9]. Increasing evidence suggests an association between preeclampsia or eclampsia and the risk for latter developing hypertension, atherosclerosis, ischemic heart disease, congestive heart failure, stroke, and deep venous thrombosis, and metabolic syndrome [10-15]. Increased risk for ischemic heart disease, myocardial infarcts, heart failure, and ischemic stroke has also been observed among women with gestational hypertension [9]. Women with a history of pregnancy complicated by intrauterine growth restriction and low infant birth weight are at a higher risk for subsequent ischemic heart disease as well [16]. Epidemiologic and experimental data strongly indicate that children born to a pregnancy complicated by preeclampsia have an unique, life time cardiovascular risk profile that is present from early life, and represent a population that may benefit from early implementation of primary prevention strategies [17]. Childhood obesity, hypertension, and diabetes are the most common intermediate and long-term health consequences of fetal undernutrition caused by placental insufficiency $[8,18]$. Interestingly, familial predisposition to preeclampsia occurs. Men and women exposed to preeclampsia in utero were more likely to trigger preeclampsia in their partners or develop preeclampsia, respectively [19-21].

MicroRNAs belong to the family of small noncoding RNAs (18-25 nucleotides) that regulate gene expression at the posttranscriptional level by degrading or blocking translation of target messenger RNA (mRNA) [22, 23]. MicroRNA analyses indicate that a variety of tissues display microRNA expression profiles that are significantly different from normal tissues [24], which may be useful for a wide range of applications in clinical diagnostics [25]. Recent studies have shown that preeclampsia and fetal growth restriction are associated with alterations in microRNA expression in the placenta [26-45].

The aim of the present study was to explore placental tissue expression profile of microRNAs known to be involved in the onset of diverse cardiovascular and cerebrovascular diseases (miR-1-3p, miR-16-5p, miR-17-5p, miR-20a-5p, miR-20b-5p, miR-21-5p, miR-23a-3p, miR24-3p, miR-26a-5p, miR-29a-3p, miR-33a-5p, miR-92a-3p, miR-100-5p, miR-103a-3p, miR122-5p, miR-125b-5p, miR-126-3p, miR-130b-3p, miR-133a-3p, miR-143-3p, miR-145-5p, 
miR-146a-5p, miR-155-5p, miR-181a-5p, miR-195-5p, miR-199a-5p, miR-208a-3p, miR-2103p, miR-221-3p, miR-342-3p, miR-499a-5p, and miR-574-3p).

We focus mainly on those microRNAs playing a role in pathogenesis of dyslipidaemia (miR-1-3p, miR-21-5p, miR-33a-5p, miR-122-5p, miR-146a-5p, miR-155-5p) [46-63], hypertension (miR-21-5p, miR-143-3p, miR-145-5p, miR-181a-5p, miR-208a-3p) [64-70], vascular inflammation (miR-29a-3p, miR-126-3p, miR-146a-5p, miR-155-5p, miR-195-5p, miR-2103p, miR-221-3p) [71-73], insulin resistance and diabetes (miR-20b-5p, miR-21-5p, miR-243p, miR-26a-5p, miR-29a-3p, miR-103a-3p, miR-126-3p, miR-133a-3p, miR-181a-5p) [74, 75], atherosclerosis (miR-21-5p, miR-33a-5p, miR-126-3p, miR-143-3p, miR-145-5p, miR155-5p) [76-82], angiogenesis (miR-16-5p, miR-17-5p, miR-20a-5p, miR-21-5p, miR-92-3p, miR-100-5p, miR-126-3p, miR-210-3p, miR-221-3p) [83-85], coronary artery disease (miR-13p, miR-17-5p, miR-20a-5p, miR-21-5p, miR-92-3p, miR-126-3p, miR-133a-3p, miR-143-3p, miR-145-5p, miR-155-5p, miR-181a-5p, miR-195-5p, miR-208a-3p, miR-221-3p) [83, 86-91], myocardial infarction and heart failure (miR-1-3p, miR-16-5p, miR-17-5p, miR-20b-5p, miR21-5p, miR-23a-3p, miR-24-3p, miR-26a-5p, miR-29a-3p, miR-92-3p, miR-100-5p, miR-1225p, miR-125b-5p, miR-126-3p, miR-103a-3p, miR-133a-3p, miR-181a-5p, miR-195-5p, miR199a-5p, miR-208a-3p, miR-210-3p, miR-499a-5p) [92-125].

To our knowledge, no study on cardiovascular and cerebrovascular microRNA expression in placental tissues derived from gestational hypertension has been carried out. Our study also describes, for the first time, placental expression of these microRNAs in preeclampsia (miR23a-3p, miR-24-3p, miR-33a-5p, miR-92-3p, miR-100-5p, miR-103a-3p, miR-122-5p, miR125b-5p, miR-130b-3p, miR-133a-3p, miR-143-3p, miR-145-5p, miR-146a-5p, miR-199a-5p, miR-208a-3p, miR-221-3p, miR-499a-5p, and miR-574-3p) or intrauterine growth restriction (miR-1-3p, miR-17-5p, miR-20a-5p, miR-20b-5p, miR-21-5p, miR-23a-3p, miR-24-3p, miR26a-5p, miR-29a-3p, miR-33a-5p, miR-92-3p, miR-100-5p, miR-103a-3p, miR-122-5p, miR125b-5p, miR-126-3p, miR-130b-3p, miR-133a-3p, miR-143-3p, miR-145-5p, miR-146a-5p, miR-155-5p, miR-181a-5p, miR-195-5p, miR-199a-5p, miR-208a-3p, miR-210-3p, miR-2213p, miR-342-3p, miR-499a-5p, and miR-574-3p).

\section{Materials and Methods}

\section{Patients}

The study was retrospective. The studied cohort consisted of 170 consecutive Caucasian pregnant women involving 35 pregnancies with gestational hypertension $(\mathrm{GH}), 80$ pregnancies with clinically established preeclampsia (PE), 35 pregnancies complicated by intrauterine growth restriction (IUGR), and 20 normal pregnancies. Of the 80 patients with preeclampsia, 34 had symptoms of mild preeclampsia and 46 were diagnosed with severe preeclampsia. Twenty-nine preeclamptic patients required delivery before 34 weeks of gestation and 51 patients delivered after 34 weeks of gestation. Preeclampsia occurred both in previously normotensive patients (57 cases), and was superimposed on pre-existing hypertension (23 cases). Eleven growth-retarded foetuses were delivered before 34 weeks of gestation and 24 after 34 weeks of gestation. Oligohydramnios or anhydramnios were present in 15 growth-restricted foetuses.

An examination of blood flow (Doppler ultrasonography) showed an abnormal pulsatility index (PI) in the umbilical artery (13 preeclampsia and 19 IUGR) and/or in the middle cerebral artery (11 preeclampsia and 11 IUGR). The cerebro-placental ratio (CPR), expressed as a ratio between the middle cerebral artery and the umbilical artery pulsatility indexes was below the fifth percentile in 30 cases (13 preeclampsia and 17 IUGR). Absent or reversed end-diastolic velocity waveforms in the umbilical artery occurred in 4 cases (1 preeclampsia and 3 IUGR). 
Table 1. The clinical characteristics of normal and complicated pregnancies.

\begin{tabular}{|c|c|c|c|c|}
\hline & $\begin{array}{l}\text { Healthy pregnant women } \\
(\mathrm{n}=20)\end{array}$ & $\begin{array}{l}\text { Preeclamptic patients } \\
(\mathrm{n}=\mathbf{8 0})\end{array}$ & $\begin{array}{l}\text { IUGR patients } \\
(n=35)\end{array}$ & $\begin{array}{l}\text { GH patients } \\
(n=35)\end{array}$ \\
\hline Age (years) & $30(26.5-33)$ & $33(30-36)$ & $30(27-31)$ & $30(28-31,5)$ \\
\hline \multicolumn{5}{|l|}{ Blood pressure $(\mathrm{mmHg})$} \\
\hline Systolic & $118(110.5-119.5)$ & $155(143-164.5)$ & $120(115-131.3)$ & $151(144-161,5)$ \\
\hline Diastolic & $72(70-82)$ & $98(90-101)$ & $75.5(70-84.3)$ & $95,5(90,75-100)$ \\
\hline Proteinuria (g/24h) & None & $1.1(0.58-3.59)$ & None & None \\
\hline Gestational age at delivery (weeks) & $40(38-41)$ & $36(33-38)$ & $36.5(31-38)$ & 39 (39-39) \\
\hline Pregnancy body mass index & $26.1(24.8-27.9)$ & $29.1(26.4-32.0)$ & $26.4(24.3-28.3)$ & $30.2(27.6-34.8)$ \\
\hline Fetal birth weight (grams) & $3420(3170-3750)$ & $2650(1650-3210)$ & $2120(1560-2490)$ & $3320(2930-3510)$ \\
\hline \multicolumn{5}{|l|}{ Mode of delivery } \\
\hline Vaginal & $18(90 \%)$ & $14(17.5 \%)$ & $9(25.7 \%)$ & $25(71.4 \%)$ \\
\hline Cesarian section & $2(10 \%)$ & $66(82.5 \%)$ & $26(74.3 \%)$ & $10(28.6 \%)$ \\
\hline \multicolumn{5}{|l|}{ Fetal sex } \\
\hline Boy & $11(55 \%)$ & $34(42.5 \%)$ & $17(48.6 \%)$ & $16(45.7 \%)$ \\
\hline Girl & $9(45 \%)$ & $46(57.5 \%)$ & 18 (51.4\%) & 19 (54.3\%) \\
\hline \multicolumn{5}{|l|}{ Glukose status } \\
\hline Normal & 19 (95\%) & 77 (96.2\%) & $34(97.1 \%)$ & $35(100 \%)$ \\
\hline GDM/DM & $1(5 \%)$ & 3 (3.8\%) & $1(2.9 \%)$ & 0 \\
\hline
\end{tabular}

Data are presented as median (25-75 percentile) for continuous variables and as number (percent) for categorical variables.

doi:10.1371/journal.pone.0138383.t001

The clinical characteristics of normal and complicated pregnancies are presented in Table 1.

Women with normal pregnancies were defined as those without medical, obstetrical, or surgical complications at the time of the study and who subsequently delivered full term, singleton healthy infants weighing $>2500 \mathrm{~g}$ after 37 completed weeks of gestation. Gestational hypertension was defined as high blood pressure that developed after the twentieth week of pregnancy.

Preeclampsia was defined as blood pressure $>140 / 90 \mathrm{mmHg}$ in two determinations 4 hours apart that was associated with proteinuria $>300 \mathrm{mg} / 24 \mathrm{~h}$ after 20 weeks of gestation [3]. Severe preeclampsia was diagnosed by the presence of one or more of the following findings: 1 ) a systolic blood pressure $>160 \mathrm{mmHg}$ or a diastolic blood pressure $>110 \mathrm{mmHg}$, 2) proteinuria greater than $5 \mathrm{~g}$ of protein in a 24-hour sample, 3) very low urine output (less than $500 \mathrm{ml}$ in $24 \mathrm{~h}$ ), 4) signs of respiratory problems (pulmonary oedema or cyanosis), 5) impairment of liver function, 6) signs of central nervous system problems (severe headache, visual disturbances), 7) pain in the epigastric area or right upper quadrant, 8) thrombocytopenia, and 9) the presence of severe fetal growth restriction [3].

Fetal growth restriction was diagnosed when the estimated fetal weight (EFW), calculated using the Hadlock formula (Astraia Software $\mathrm{GmbH}$ ), was below the tenth percentile for the evaluated gestational age, adjustments were made for the appropriate population standards of the Czech Republic. In addition to fetal weight below the threshold of the $10^{\text {th }}$ percentile IUGR foetuses had at least one of the following pathological finding: an abnormal pulsatility index in the umbilical artery, absent or reversed end-diastolic velocity waveforms in the umbilical artery, an abnormal pulsatility index in the middle cerebral artery, a sign of a blood flow centralisation, and a deficiency of amniotic fluid (anhydramnios and oligohydramnios).

Centralization of the fetal circulation represents a protective reaction of the fetus against hypoxia that manifests itself in redistribution of the circulation in the brain, liver and heart at the expense of the flow reduction in the periphery $[126,127]$. The cerebroplacental ratio (CPR) 
quantifies redistribution of cardiac output by dividing Doppler indices from representative cerebral and fetoplacental vessels.

Patients with a complicated gestation demonstrating premature rupture of membranes, in utero infections, fetal anomalies or chromosomal abnormalities, and fetal demise in utero or stillbirth were excluded from the study.

All patients who participated in this study provided written informed consent. The study was approved by the Ethics Committees of the Third Faculty of Medicine, Charles University in Prague and the Institute for the Care of the Mother and Child.

\section{Processing of samples}

Samples of placenta were collected at the Institute for the Care of the Mother and Child (Prague, CZ) and stored at $-80^{\circ} \mathrm{C}$ until further processing.

Total RNA was extracted from $30 \mathrm{mg}$ of placental tissue preserved in RNAlater (Ambion, Austin, USA) followed by an enrichment procedure for small RNAs (siRNAs, microRNAs), according to manufacturer's instructions using a mirVana microRNA Isolation kit (Ambion, Austin, USA). To minimize DNA contamination, we treated the eluted RNA with $5 \mu \mathrm{L}$ of DNase I (Fermentas International, Ontario, Canada) for $30 \mathrm{~min}$ at $37^{\circ} \mathrm{C}$. Using this novel approach, a RNA fraction highly enriched in RNA species $<200$ nt was obtained, whose concentration and quality was assessed using a NanoDrop ND-1000 spectrophotometer (NanoDrop Technologies, USA). The A(260/280) absorbance ratio of isolated RNA was 1.8-2.0, demonstrating that the RNA fraction was pure and could be used for analysis. Additionally, the $\mathrm{A}(260 / 230)$ ratio was greater than 1.6, demonstrating negligible contamination by polysaccharides.

\section{Reverse transcriptase reaction using a stem-loop primer}

Each of the 32 microRNAs (miR-1-3p, miR-16-5p, miR-17-5p, miR-20a-5p, miR-20b-5p, miR-21-5p, miR-23a-3p, miR-24-3p, miR-26a-5p, miR-29a-3p, miR-33a-5p, miR-92a-3p, miR-100-5p, miR-103a-3p, miR-122-5p, miR-125b-5p, miR-126-3p, miR-130b-3p, miR-133a3p, miR-143-3p, miR-145-5p, miR-146a-5p, miR-155-5p, miR-181a-5p, miR-195-5p, miR199a-5p, miR-208a-3p, miR-210-3p, miR-221-3p, miR-342-3p, miR-499a-5p, and miR-574$3 p$ ) was reverse transcribed into complementary DNA (cDNA) using a TaqMan MicroRNA Assay, containing microRNA-specific stem-loop RT primers (Table 2), and TaqMan MicroRNA Reverse Transcription Kit (Applied Biosystems, Branchburg, USA) in a total reaction volume of $10 \mu \mathrm{L}$, according to manufacturer's instructions. Reverse transcriptase reactions were performed using a 7500 Real-Time PCR system (Applied Biosystems, Branchburg, USA) with the following thermal cycling parameters: 30 minutes at $16^{\circ} \mathrm{C}, 30$ minutes at $42^{\circ} \mathrm{C}, 5$ minutes at $85^{\circ} \mathrm{C}$, and then held at $4^{\circ} \mathrm{C}$. Finally, $12 \mathrm{ng}$ of the RNA template was used for each RT reaction.

\section{Relative quantification of microRNAs by real-time PCR}

$4 \mu \mathrm{L}$ of cDNA, corresponding to each selected microRNA, were mixed with specific primers and the TaqMan MGB probe (TaqMan MicroRNA Assay, Applied Biosystems, Branchburg, USA), and the ingredients of the TaqMan Universal PCR Master Mix (Applied Biosystems, Branchburg, USA) in a total reaction volume of $20 \mu \mathrm{L}$. TaqMan PCR conditions were set as described in the TaqMan guidelines. The analysis was performed using a 7500 Real-Time PCR System. All PCRs were performed in duplicates. Multiple negative controls such as NTC (water instead of cDNA sample), NAC (non-transcribed RNA samples), and genomic DNA (isolated from equal biological samples) did not generate any signal during PCR reactions. Each sample 
Table 2. Characteristics of microRNAs involved in the study.

\begin{tabular}{|c|c|c|c|}
\hline Assay name & miRBase ID & NCBI Location Chromosome & microRNA sequence \\
\hline hsa-miR-1 & hsa-miR-1-3p & Chr20: 61151513-61151583 [+] & 5'-UGGAAUGUAAAGAAGUAUGUAU-3' \\
\hline hsa-miR-16 & hsa-miR-16-5p & Chr13: 50623109-50623197 [-] & 5'-UAGCAGCACGUAAAUAUUGGCG- 3' \\
\hline hsa-miR-17 & hsa-miR-17-5p & Chr13: 92002859-92002942 [+] & 5'-CAAAGUGCUUACAGUGCAGGUAG-3' \\
\hline hsa-miR-20a & hsa-miR-20a-5p & Chr13: 92003319-92003389 [+] & 5'-UAAAGUGCUUAUAGUGCAGGUAG-3' \\
\hline hsa-miR-20b & hsa-miR-20b-5p & ChrX: 133303839-133303907 [-] & 5'-CAAAGUGCUCAUAGUGCAGGUAG-3' \\
\hline hsa-miR-21 & hsa-miR-21-5p & Chr17: 57918627-57918698 [+] & 5'-UAGCUUAUCAGACUGAUGUUGA-3' \\
\hline hsa-miR-23a & hsa-miR-23a-3p & Chr19: 13947401-13947473 [-] & 5'-AUCACAUUGCCAGGGAUUUCC-3' \\
\hline hsa-miR-24 & hsa-miR-24-3p & Chr19: 13947101-13947173 [-] & 5'-UGGCUCAGUUCAGCAGGAACAG-3' \\
\hline hsa-miR-26a & hsa-miR-26a-5p & Chr3: 38010895-38010971 [+] & 5'-UUCAAGUAAUCCAGGAUAGGCU-3' \\
\hline hsa-miR-29a & hsa-miR-29a-3p & Chr7: 130561506-130561569 [-] & 5'-UAGCACCAUCUGAAAUCGGUUA-3' \\
\hline hsa-miR-33a & hsa-miR-33a-5p & Chr22: 42296948-42297016 [+] & 5'-GUGCAUUGUAGUUGCAUUGCA-3' \\
\hline hsa-miR-92a & hsa-miR-92-3p & Chr13: 92003568-92003645 [+] & 5'-UAUUGCACUUGUCCCGGCCUGU-3' \\
\hline hsa-miR-100 & hsa-miR-100-5p & Chr11: 122022937-122023016 [-] & 5'-AACCCGUAGAUCCGAACUUGUG-3' \\
\hline hsa-miR-103 & hsa-miR-103a-3p & Chr20: 3898141-3898218 [+] & 5'-AGCAGCAUUGUACAGGGCUAUGA-3' \\
\hline hsa-miR-122 & hsa-miR-122-5p & Chr18: 56118306-56118390 [+] & 5'-UGGAGUGUGACAAUGGUGUUUG-3' \\
\hline hsa-miR-125b & hsa-miR-125b-5p & Chr21: 17962557-17962645 [+] & 5'-UCCCUGAGACCCUAACUUGUGA-3' \\
\hline hsa-miR-126 & hsa-miR-126-3p & Chr9: 139565054-139565138 [+] & 5'-UCGUACCGUGAGUAAUAAUGCG-3' \\
\hline hsa-miR-130b & hsa-miR-130b-3p & Chr22: 22007593-22007674 [+] & 5'-CAGUGCAAUGAUGAAAGGGCAU-3' \\
\hline hsa-miR-133a & hsa-miR-133-3p & Chr20: 61162119-61162220 [+] & 5'-UUUGGUCCCCUUCAACCAGCUG-3' \\
\hline hsa-miR-143 & hsa-miR-143-3p & Chr5: 148808481-148808586 [+] & 5'-UGAGAUGAAGCACUGUAGCUC-3' \\
\hline hsa-miR-145 & hsa-miR-145-5p & Chr5: 148810209-148810296 [+] & 5'-GUCCAGUUUUCCCAGGAAUCCCU-3' \\
\hline hsa-miR-146a & hsa-miR-146a-5p & Chr5: 159912359-159912457 [+] & 5'-UGAGAACUGAAUUCCAUGGGUU-3' \\
\hline hsa-miR-155 & hsa-miR-155-5p & Chr21: 26946292-26946356 [+] & 5'-UUAAUGCUAAUCGUGAUAGGGGU-3' \\
\hline hsa-miR-181a & hsa-miR-181a-5p & Chr9: $127454721-127454830[+]$ & 5'-AACAUUCAACGCUGUCGGUGAGU-3' \\
\hline hsa-miR-195 & hsa-miR-195-5p & Chr17: 6920934-6921020 [-] & 5'-UAGCAGCACAGAAAUAUUGGC-3' \\
\hline hsa-miR-199a & hsa-miR-199a-5p & Chr19: 10928102-10928172 [-] & 5'-CCCAGUGUUCAGACUACCUGUUC-3' \\
\hline hsa-miR-208 & hsa-miR-208a-3p & Chr14: 23857805-23857875 [-] & 5'-AUAAGACGAGCAAAAAGCUUGU-3' \\
\hline hsa-miR-210 & hsa-miR-210-3p & Chr11: 568089-568198 [-] & 5'-CUGUGCGUGUGACAGCGGCUGA-3' \\
\hline hsa-miR-221 & hsa-miR-221-3p & ChrX: 45605585-45605694 [-] & 5'-AGCUACAUUGUCUGCUGGGUUUC-3' \\
\hline hsa-miR-342-3p & hsa-miR-342-3p & Chr14: $100575992-100576090[+]$ & 5'-UCUCACACAGAAAUCGCACCCGU-3' \\
\hline mmu-miR-499 & hsa-miR-499a-5p & Chr20: $33578179-33578300[+]$ & 5'-UUAAGACUUGCAGUGAUGUUU-3' \\
\hline hsa-miR-574-3p & hsa-miR-574-3p & Chr4: 38869653-38869748 [+] & 5'-CACGCUCAUGCACACACCCACA-3' \\
\hline
\end{tabular}

doi:10.1371/journal.pone.0138383.t002

was considered positive if the amplification signal occurred before the $40^{\text {th }}$ threshold cycle $(\mathrm{Ct}<40)$.

The expression of particular microRNA was determined using the comparative Ct method [128] relative to normalization factor (geometric mean of two selected endogenous controls) [129]. Stability of candidate endogenous controls was evaluated using NormFinder (available: http://moma.dk/normfinder-software), an ANOVA-based model, which returns standard deviation (SD) value, accumulated SD (Acc.SD) value and stability value, named variability [130-132]. In total, expression of 19 candidate endogenous controls (HY3, RNU6B, RNU19, RNU24, RNU38B, RNU43, RNU44, RNU48, RNU49, RNU58A, RNU58B, RNU66, RPL21, U6 snRNA, U18, U47, U54, U75, and Z30) was investigated in placental tissue samples.

The identification and validation analyses of suitable endogenous controls for normalization in placental tissues revealed that RNU58A and U54 were equally expressed between patients with normal course of gestation, preeclampsia and IUGR. In case of gestational hypertension 
qPCR data were normalized to U6snRNA and RNU66. These small nucleolar and nuclear RNAs also served as positive controls for successful extraction of RNA from all samples and were used as internal controls for variations during the preparation of RNA, cDNA synthesis, and real-time PCR.

RNA fraction highly enriched for small RNA isolated from the fetal part of one randomly selected placenta derived from gestation with normal course (the part of the placenta derived from the chorionic sac that encloses the embryo, consisting of the chorionic plate and villi) was used as a reference sample for relative quantification throughout the study.

\section{Statistical analysis}

Data normality was assessed using the Shapiro-Wilk test, which showed that our data did not follow a normal distribution. Therefore, microRNA levels were compared between groups using non-parametric tests (the Mann-Whitney $\mathrm{U}$ test for the comparison between two groups and the Kruskal-Wallis test for the comparison among multiple groups). Since the Bonferroni correction was used to address the problem of multiple comparisons, the significance level was established at a $p$-value of $\mathrm{p}<0.025$ for the comparison between two groups and $p$-value of $\mathrm{p}<0.017$ for the comparison among multiple groups.

Data analysis was performed and box plots were generated using Statistica software (version 9.0; StatSoft, Inc., USA). Each box encompasses the median (dark horizontal line) of log-normalized gene expression values for microRNAs of interest in cohorts; the upper and lower limits of the boxes represent the $75^{\text {th }}$ and $25^{\text {th }}$ percentiles, respectively. The upper and lower whiskers represent the maximum and minimum values that are no more than 1.5 times the span of the interquartile range (range of the values between the $25^{\text {th }}$ and the $75^{\text {th }}$ percentiles). Outliers are indicated by circles and extremes by asterisks.

\section{Information on microRNA-gene-Disease ontology interactions}

MiRDB (available: http://mirdb.org/miRDB/) and miRTar databases (available: http://mirtar. $\mathrm{mbc}$.nctu.edu.tw/human/) were used to predict targets of those microRNAs that have been found to be dysregulated in placental tissues of patients with pregnancy-related complications.

$\mathrm{MiRDB}$ is an online database for miRNA target prediction and functional annotations. All the targets were predicted by a bioinformatics tool, MirTarget, which was developed by analyzing thousands of miRNA-target interactions from high-throughput sequencing experiments.

Common features associated with miRNA target binding have been identified and used to predict miRNA targets with machine learning methods.

MicroRNA Target prediction (miRTar) is a tool that enables biologists easily to identify the biological functions and regulatory relationships between a group of known/putative miRNAs and protein coding genes. It also provides perspective of information on the miRNA targets on alternatively spliced transcripts.

Further, miRWalk database (available: http://www.umm.uni-heidelberg.de/apps/zmf/ mirwalk/) and the Validated Targets module were used to provide information on experimentally verified interaction between appropriate microRNA and specific genes on human disease ontologies such as heart disease, myocardial infarction, congestive heart failure, vascular disease, cerebral infarction, hypertension, obesity, atherosclerosis, hypercholesterolemia and diabetic angiopathy, insulin resistance and diabetes [133]. miRWalk is a comprehensive database that provides information on miRNA from human, mouse, and rat on their predicted as well as validated binding sites on their target genes. Information on miRNA-target interactions on 2,035 disease ontologies (DO), 6,727 Human Phenotype ontologies (HPO) and 4,980 OMIM disorders is available. 
Best gene

RNU58A

Stability value

0,069

Best combination of two genes

RNU58A and U54

Stability value for best combination of two genes

0,056

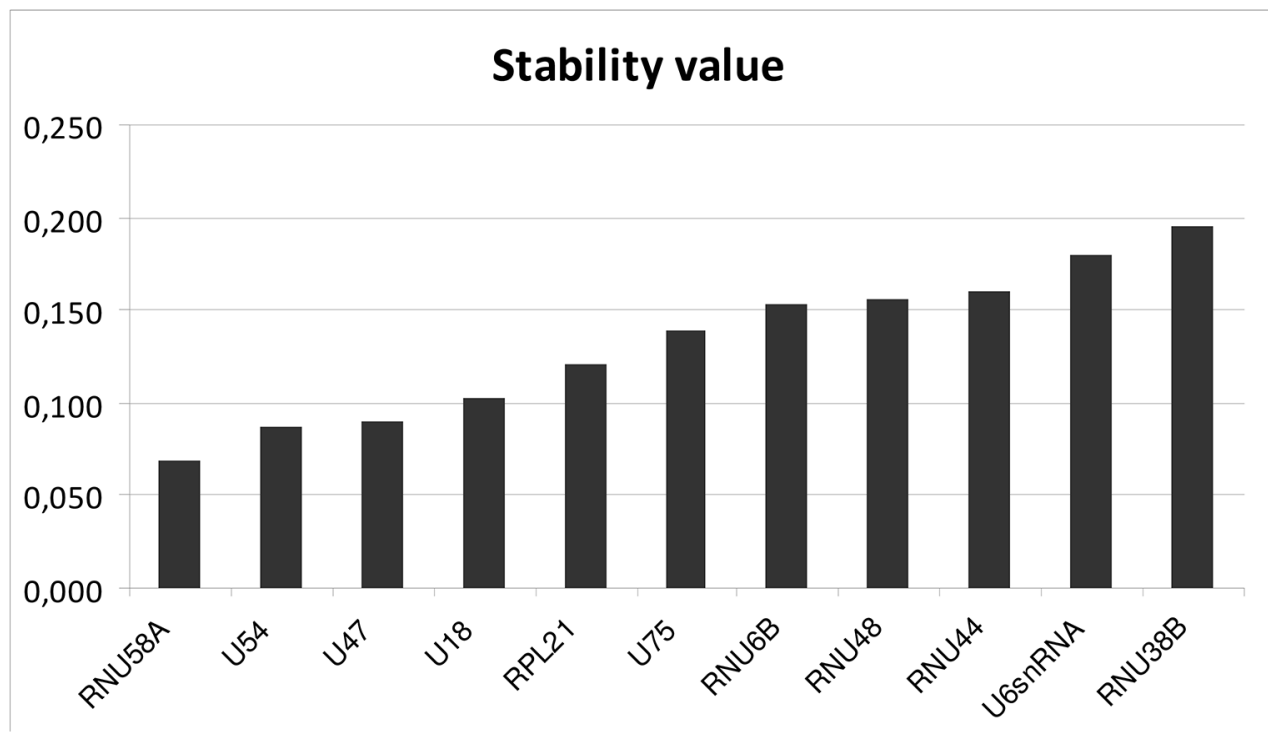

Fig 1. Identification of the most suitable endogenous controls in placental tissues of patients with preeclampsia and IUGR. The identification and validation analyses reveal that RNU58A and U54 are equally expressed between patients with normal course of gestation, preeclampsia and IUGR.

doi:10.1371/journal.pone.0138383.g001

\section{Results}

\section{Selection and validation of endogenous controls for microRNA expression studies in placental tissues affected by pregnancy-related complications}

Expression of 19 candidate endogenous controls (HY3, RNU6B, RNU19, RNU24, RNU38B, RNU43, RNU44, RNU48, RNU49, RNU58A, RNU58B, RNU66, RPL21, U6 snRNA, U18, U47, U54, U75, and Z30) was investigated in placental tissue samples obtained from 80 patients (20 normal gestation, $20 \mathrm{GH}, 20 \mathrm{PE}$ and 20 IUGR) using NormFinder [130-132]. The results were then validated using larger group of samples $(20$ normal gestations, $35 \mathrm{GH}, 80 \mathrm{PE}$ and 35 IUGR). In both analyses, RNU58A and U54 were identified as the most stable ncRNA and equally expressed between patients with normal and abnormal course of gestation (preeclampsia and IUGR), (Fig 1). The equivalent expression between normal gestation and gestational hypertension groups was confirmed for other two candidate endogenous controls: U6snRNA and RNU66 (Fig 2). Therefore, these small nucleolar and nuclear RNAs were selected as the most suitable endogenous controls for normalization of microRNA qPCR expression studies performed on placental tissues affected by pregnancy-related complications.

\section{Exclusion of miR-33a-5p and miR-208a-3p from further analyses}

Unfortunately, miR-33a-5p and miR-208a-3p displayed repeatedly poor amplification curves in placental tissue samples, and therefore were excluded from further analyses. 
Cardiovascular and cerebrovascular disease associated microRNAs are dysregulated in placental tissues affected with gestational hypertension, preeclampsia and intrauterine growth restriction

Gene expression of microRNAs was compared between normal and complicated pregnancies. Gene expression of microRNAs was analysed in relation to the severity of the disease with respect to the degree of clinical signs (mild vs. severe preeclampsia, absence vs. presence of oligohydramnios or anhydramnios in growth-restricted foetuses) and delivery dates (before or after 34 weeks of gestation). Additionally, the association between microRNA gene expression and the occurrence of previous hypertension in the group of patients with preeclampsia was determined.

The association between gene expression of particular microRNAs and Doppler ultrasonography parameters (the pulsatility index in the umbilical artery, the pulsatility index in the middle cerebral artery and the cerebroplacental ratio) was analysed in the cohort of pregnancies complicated with preeclampsia or intrauterine growth restriction. Just the results that reached a statistical significance or displayed a trend toward higher or lower microRNA levels in placental tissues derived from abnormal cases are presented below.

Up-regulation of miR-499a-5p is a common feature of gestational hypertension, preeclampsia and IUGR. After the correction for multiple comparisons, it was found that the expression of miR-499a-5p differed significantly between the control group and pregnancies affected with pregnancy complications. Higher expression rates were detected in patients with gestational hypertension ( $\mathrm{p}=0.013)$, preeclampsia $(\mathrm{p}<0.001)$, and intrauterine growth restriction $(\mathrm{p}=0.011)$, (Fig $3 \mathrm{~A}$ and $3 \mathrm{~B})$.

Best gene

U6snRNA

Stability value

0,129

Best combination of two genes

U6snRNA and RNU66

Stability value for best combination of two genes

0,102

\section{Stability value}

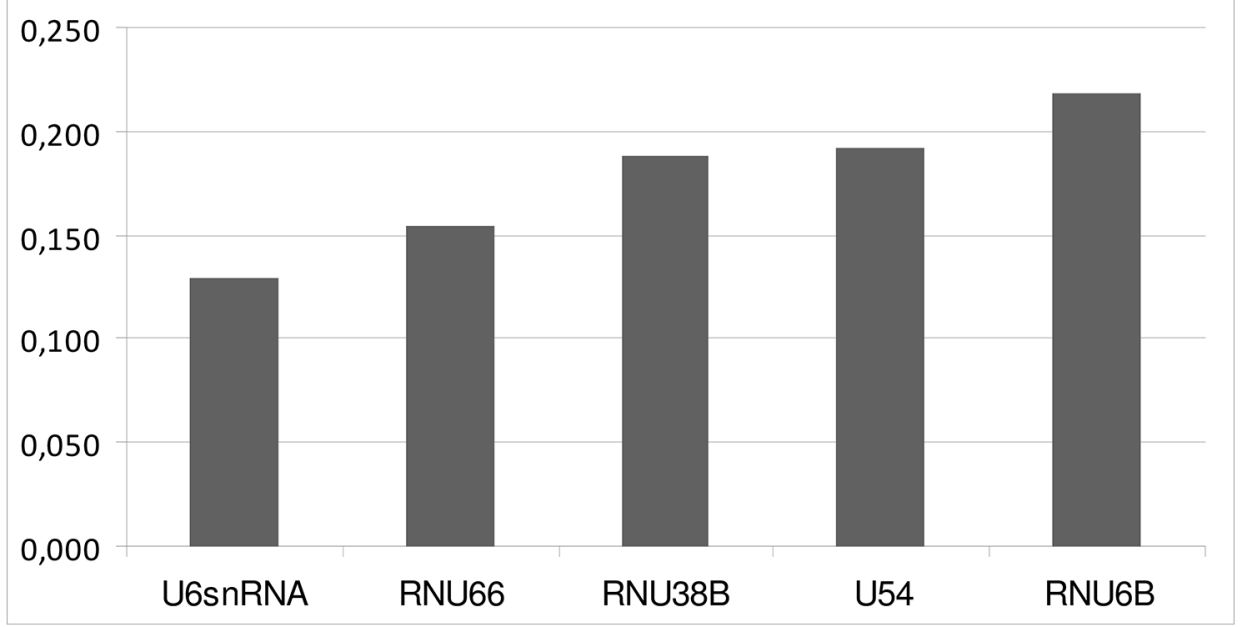

Fig 2. Identification of the most suitable endogenous controls in placental tissues of patients with gestational hypertension. The identification and validation analyses reveal that U6snRNA and RNU66 are equally expressed between patients with normal course of gestation and gestational hypertension.

doi:10.1371/journal.pone.0138383.g002 
A

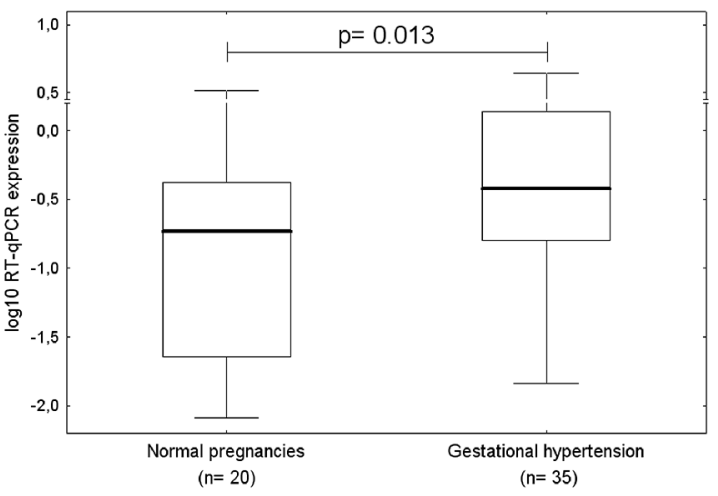

\section{C}

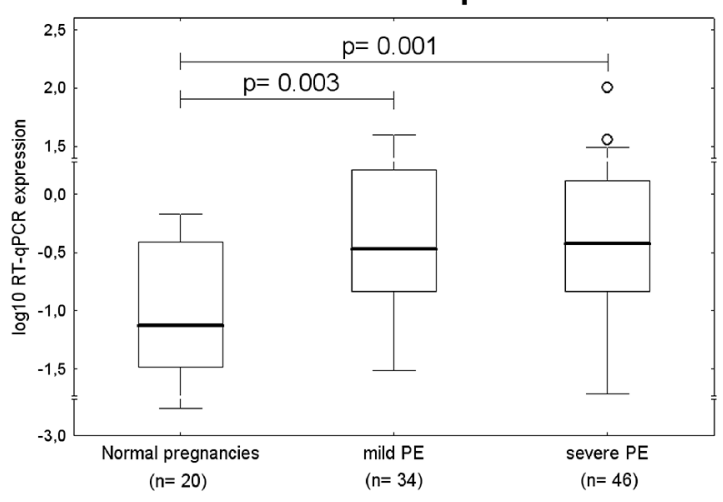

E

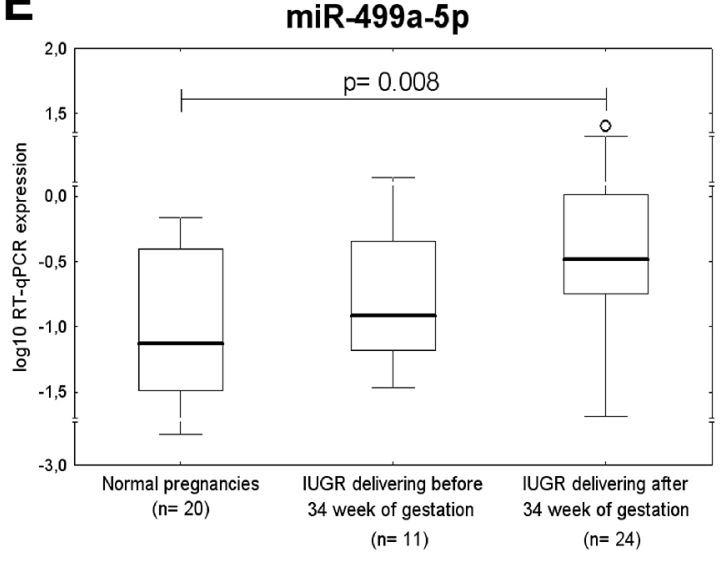

B

miR-499a-5p

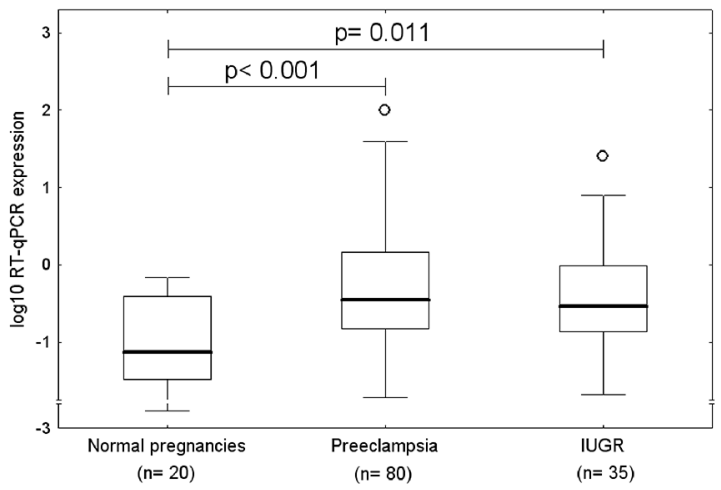

D miR-499a-5p

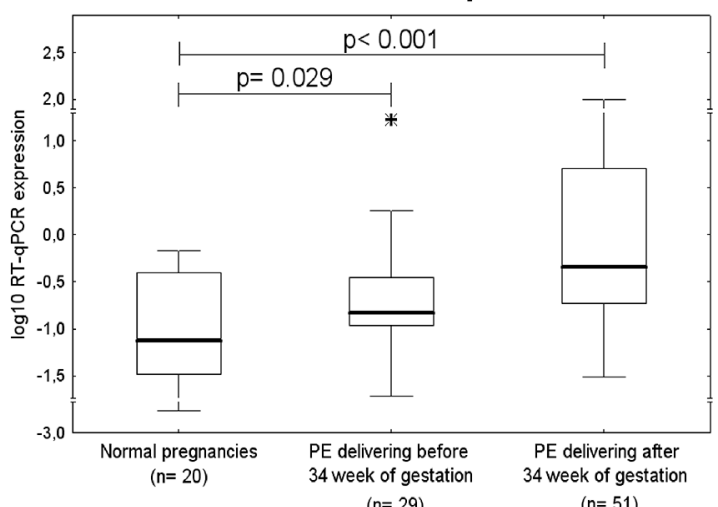

F

miR-499a-5p

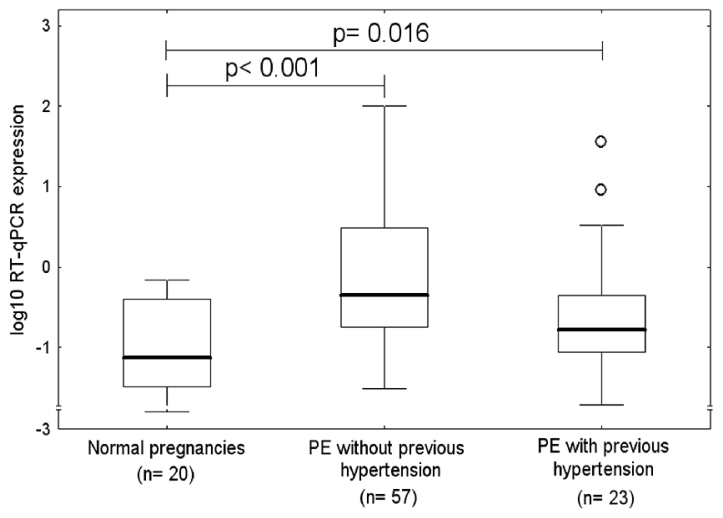

Fig 3. Up-regulation of miR-499a-5p is a common feature of gestational hypertension, preeclampsia and IUGR. Expression of miR-499a-5p differs significantly between the control group and pregnancies affected with (A) gestational hypertension, (B) preeclampsia and IUGR. Up-regulation of miR-499a$5 p$ occurs in both, mild and severe preeclampsia (C). Gene expression of miR-499a-5p differs significantly between preeclamptic pregnancies delivering after 34 week of gestation and normal pregnancies (D). The difference between preeclamptic pregnancies requiring the delivery before 34 week of gestation and controls was only a trend (D). When compared to normal pregnancies, significant up-regulation of miR-499a-5p was observed in IUGR pregnancies delivering after 34 week of gestation (E). Up-regulation of miR-499a-5p appears in patients with unexpected onset of preeclampsia as well as in those with preeclampsia superposed on chronic and/or gestational hypertension ( $F$ ).

doi:10.1371/journal.pone.0138383.g003

When compared to normal pregnancies, significant up-regulation of miR-499a-5p was observed in both, mild $(\mathrm{p}=0.003)$, and severe preeclampsia $(\mathrm{p}=0.001)$ (Fig $3 \mathrm{C})$. While gene 
expression of miR-499a-5p differed significantly between preeclamptic pregnancies delivering after 34 weeks of gestation and normal pregnancies ( $p<0.001)$, the difference between preeclamptic pregnancies requiring the delivery before 34 weeks of gestation and controls was only a trend $(\mathrm{p}=0.029)$ (Fig 3D). Similar results were achieved in case of IUGR (IUGR with the onset before 34 weeks of gestation: $\mathrm{p}=0.256$ and IUGR with the onset after 34 weeks of gestation: $\mathrm{p}=0.008)($ Fig 3E).

The statistical analyses revealed the difference between the group of preeclampsia superposed on chronic hypertension and/or gestational hypertension compared to control group $(\mathrm{p}=0.016)$. The higher expression of $m i R-499 a-5 p$ in the group of patients with unexpected onset of preeclampsia was also observed $(\mathrm{p}<0.001$ ) (Fig 3F).

Up-regulation of miR-1-3p represents a common feature of preeclamptic pregnancies delivering after 34 week of gestation and IUGR with abnormal values of flow rate in the umbilical artery. After the correction for multiple comparisons, a significant difference in $m i R-1-3 p$ expression was found between the control group and preeclampsia patients delivering after 34 weeks of gestation ( $\mathrm{p}=0.012)($ Fig $4 \mathrm{~A})$.

IUGR pregnancies with abnormal blood flow velocity waveforms also showed significantly increased expression of $m i R-1-3 p$ compared to IUGR patients with normal values of flow rate in the umbilical artery $(\mathrm{p}=0.019)$, (Fig 4B).

Down-regulation of miR-26a-5p, miR-103a-3p, and miR-145-5p represents a common feature of preeclampsia and IUGR requiring the delivery before 34 weeks of gestation. After the correction for multiple comparisons, statistical analysis revealed that placental expression of $m i R-26 a-5 p(\mathrm{p}=0.013), m i R-103 a-3 p(\mathrm{p}=0.006)$ and $m i R-145-5 p(\mathrm{p}=0.016)$, differed significantly between the control group and pregnancies affected with preeclampsia that required delivery before 34 weeks of gestation (Fig 5A, 5B and 5C). Parallel, a significant difference in $m i R-145-5 p$ expression ( $\mathrm{p}=0.011$ ) was found between IUGR requiring the delivery before 34 weeks of gestation and normal pregnancy groups (Fig 6A). A trend toward statistical significance for down-regulation of $m i R-26 a-5 p(p=0.031)$ and $m i R-103 a-3 p(p=0.047)$ was observed for IUGR pregnancies delivering before 34 weeks of gestation (Fig 6B and $6 \mathrm{C}$ ).

Down-regulation of miR-16-5p, miR-100-5p, miR-122-5p, miR-125b-5p, miR-126-3p, miR-143-3p, miR-195-5p, miR-199a-5p, miR-221-3p, miR-342-3p, and miR-574-3p represents an unique feature of IUGR requiring the delivery before 34 weeks of gestation. The down-regulation of 3 of 30 microRNAs was associated with IUGR requiring termination before 34 weeks of gestation ( $m i R-122-5 p, \mathrm{p}=0.003 ; m i R-125 b-5 p, \mathrm{p}=0.005 ; m i R-195-5 p, p=0.012)$ (Fig 7A, 7B and 7C). Several cardiovascular microRNAs showed a trend to lower expression in placental tissues derived from IUGR cases terminated before 34 weeks of gestation $(m i R-16-5 p$, $\mathrm{p}=0.018 ; m i R-100-5 p, \mathrm{p}=0.023 ; m i R-126-3 p, \mathrm{p}=0.033 ; m i R-143-3 p, \mathrm{p}=0.043 ; m i R-199 a-5 p$, $\mathrm{p}=0.043 ; m i R-221-3 p, \mathrm{p}=0.042 ; m i R-342-3 p, \mathrm{p}=0.039$ and $m i R-574-3 p, p=0.042)($ Fig $8 \mathrm{~A}-$ $8 \mathrm{H})$.

Information on microRNA-gene-Disease ontology interactions. The extensive file of predicted or verified targets of all aberrantly expressed microRNAs in placental tissues derived from patients with established gestational hypertension, preeclampsia, or intrauterine growth restriction indicate that a large group of genes may be potentially dysregulated since prenatal period of life (Table 3).

\section{Discussion}

Relative quantification of microRNA expression requires proper normalization strategy to minimize systematic and technical bias introduced at each step of microRNA quantification process $[132,134,135]$. A proper normalization of microRNA quantification requires a careful 
A $\quad$ miR-1-3p

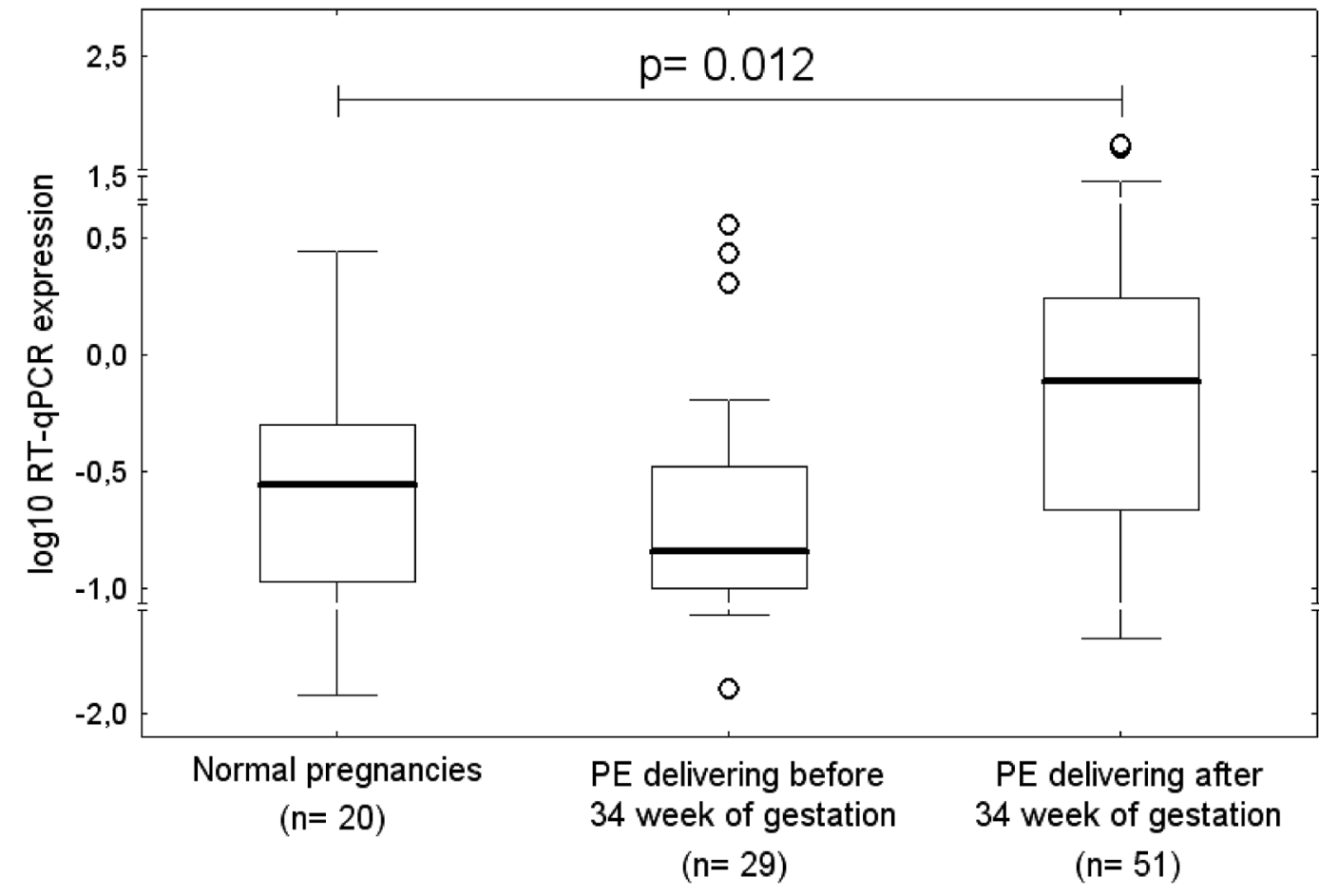

B

miR-1-3p

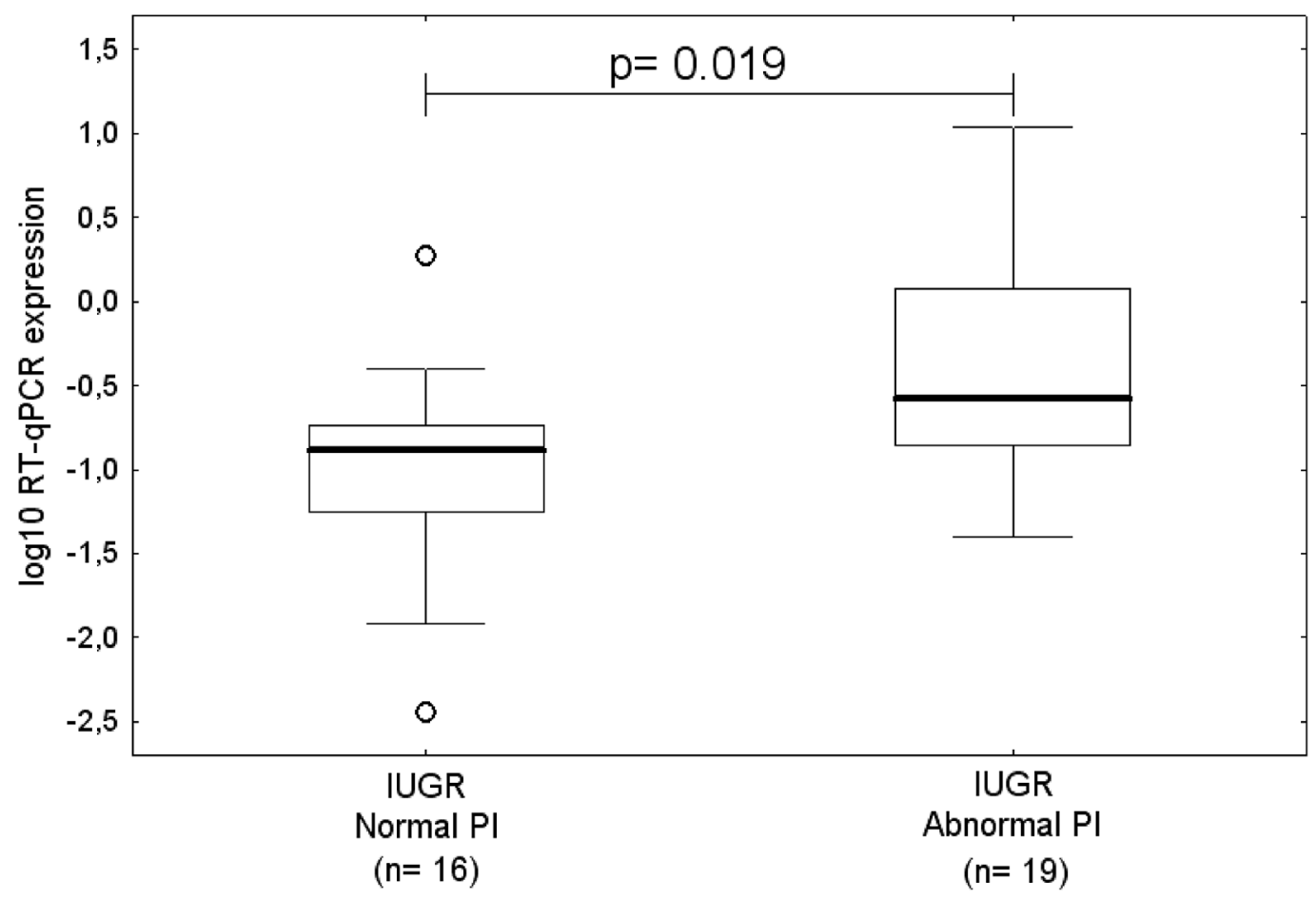

Fig 4. Up-regulation of miR-1-3p in pregnancy-related complications. Up-regulation of miR-1-3p represents a common feature of $(A)$ preeclamptic pregnancies delivering after 34 week of gestation and (B) IUGR with abnormal values of flow rate in the umbilical artery. PI; pulsatility index.

doi:10.1371/journal.pone.0138383.g004 
A
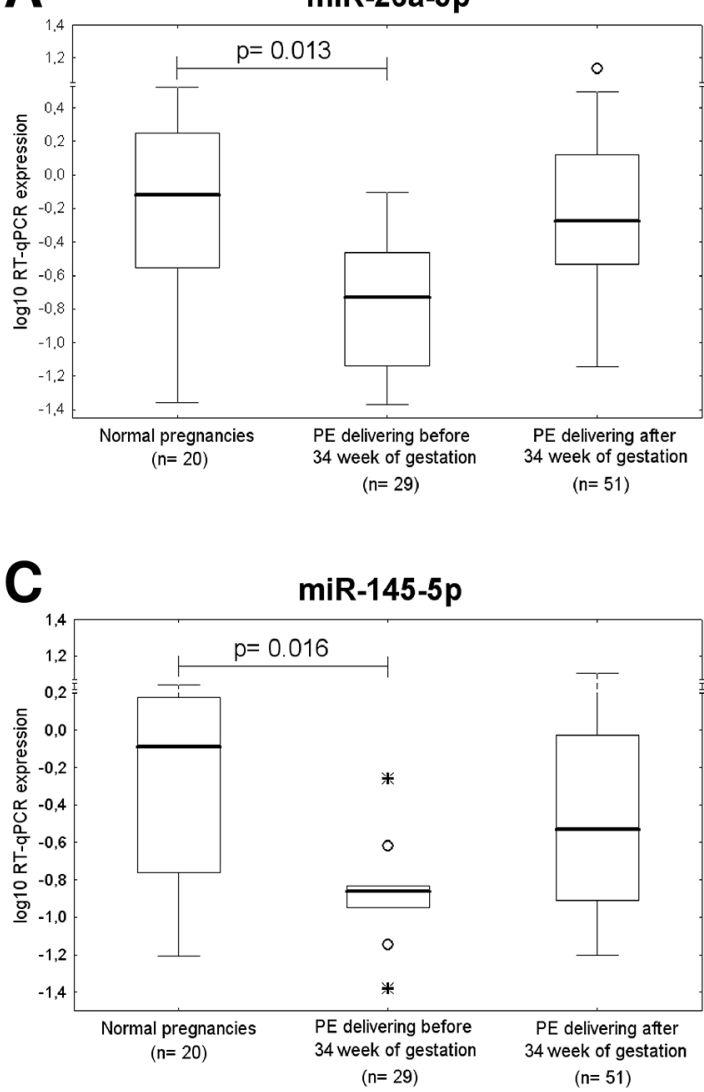

B $\quad$ miR-103a-3p

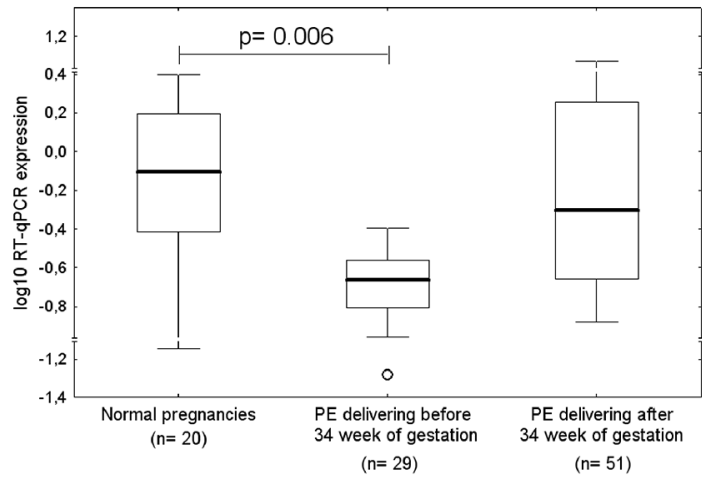

Fig 5. Down-regulation of miR-26a-5p, miR-103a-3p, and miR-145-5p in preeclampsia. Placental expression of (A) miR-26a-5p, (B) miR-103a-3p, and (C) miR-145-5p differs significantly between control group and pregnancies affected with preeclampsia that required delivery before 34 week of gestation.

doi:10.1371/journal.pone.0138383.g005

choice and validation of endogenous controls in the representative sample of the studied population $[132,136]$. No previous report described an experimental identification and validation of suitable endogenous controls for normalization in pregnancy-related complications. Thus we aimed to experimentally identify the most stable endogenous controls for normalization of microRNA qPCR expression studies in gestational hypertension, preeclampsia and intrauterine growth restriction, which comprise the most common pregnancy-related complications. Analyses performed by our group revealed that RNU58A and U54 were the most stable endogenous controls in preeclamptic and IUGR placenta tissues. On the other hand, NormFinder indicated that other two non-coding small RNA (U6snRNA and RNU66) were optimal for qPCR data normalization in $\mathrm{GH}$ placental tissues.

Most studies on microRNA profiling in placental tissues derived from pregnancy-related complication relied on arbitrarily chosen endogenous controls. U6snRNA that is the most commonly used endogenous control, was characterized by high inter-group variation in that study when its placental tissue expression was compared between preeclampsia, IUGR and normal pregnancies.

Gene expression of cardiovascular and cerebrovascular microRNAs was compared between normal and complicated pregnancies. We focus mainly on those microRNAs being previously reported to play a role in pathogenesis of dyslipidaemia, hypertension, obesity, vascular inflammation, insulin resistance and diabetes, atherosclerosis, angiogenesis, coronary artery disease, myocardial infarction and heart failure. 
A

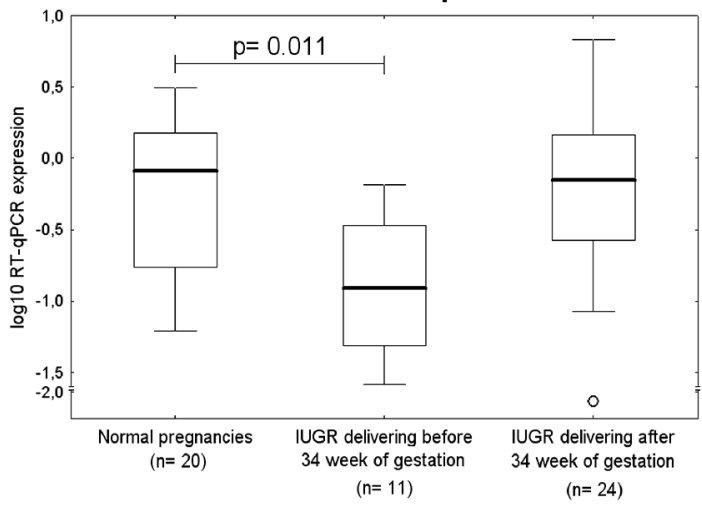

miR-103a-3p

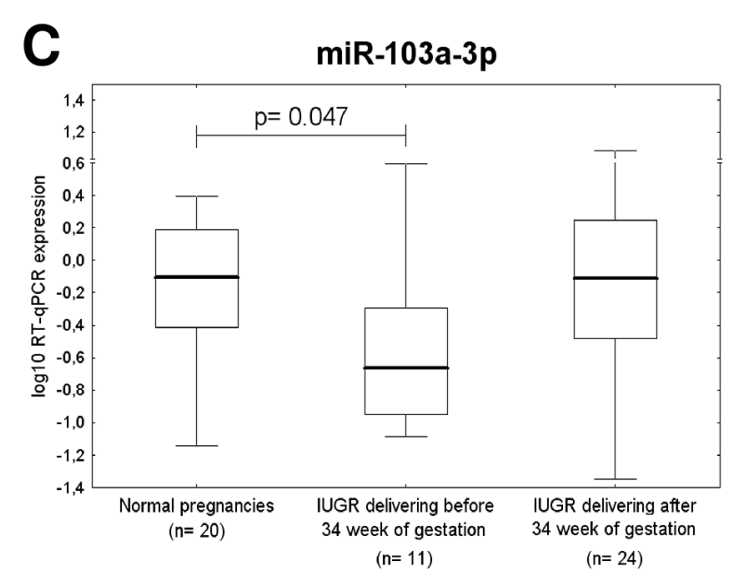

B

miR-26a-5p

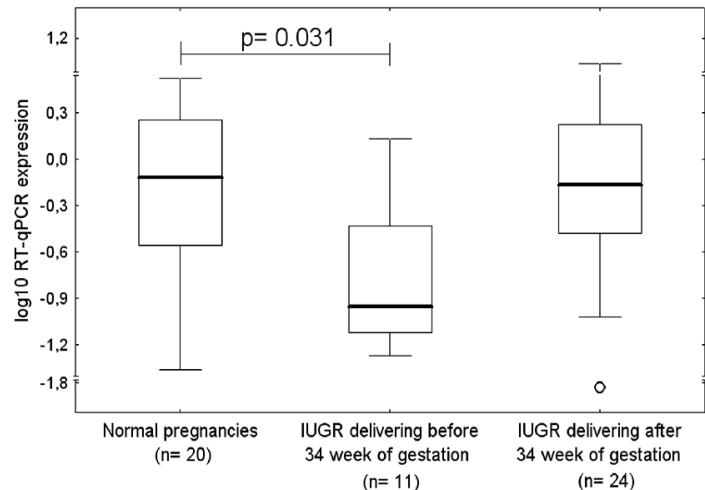

Fig 6. Down-regulation of miR-26a-5p, miR-103a-3p, and miR-145-5p in IUGR. Placental expression of miR-145-5p (A) differs significantly between the control group and pregnancies affected with IUGR that required delivery before 34 week of gestation. A trend toward statistical significance for downregulation of miR-26a-5p (B) and miR-103a-3p (C) was observed for IUGR pregnancies delivering before 34 week of gestation.

doi:10.1371/journal.pone.0138383.g006

Overall, the expression profile of studied microRNAs was different between complicated pregnancies and controls. With regard to individual pregnancy-related disorder subtypes, upregulation of only 1 out of 30 studied microRNAs was found in placental tissues derived from patients with gestational hypertension, clinically established preeclampsia and intrauterine growth restriction (miR-499a-5p).

Based on the results of our study, we further studied the association between microRNA expression in placental tissues and the severity of the disease with respect to the degree of clinical signs, delivery date (before or after 34 weeks of gestation) and Doppler ultrasound examination. Cardiovascular and cerebrovascular disease associated microRNA gene expression appeared linked to the sudden onset of severe clinical symptoms requiring urgent termination of pregnancy by Caesarean section, to avoid potentially serious maternal and perinatal outcomes. Our results showed that 3 microRNAs ( $m i R-26 a-5 p$, miR-103a-5p, miR-145-5p) were dysregulated in preeclampsia requiring termination before 34 weeks and 14 microRNAs ( $m i R$ 16-5p, miR-26a-5p, miR-100-5p, miR-103a-5p, miR-122-5p, miR-125b-5p, miR-126-3p, miR143-3p, miR-145-5p, miR-195-5p, miR-199a-5p, miR-221-3p, miR-342-3p, and miR-574-3p) were altered in IUGR terminated before 34 weeks of gestation. This data suggests the involvement of these microRNAs in the pathogenesis of preeclampsia and IUGR. 
A

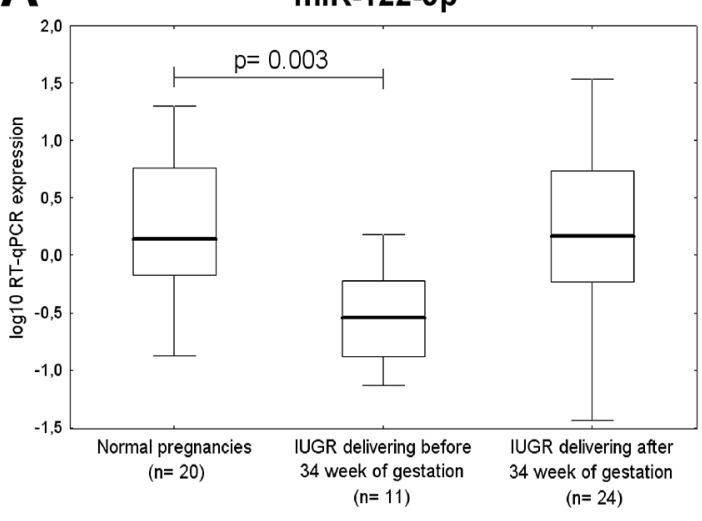

\section{C miR-195-5p}

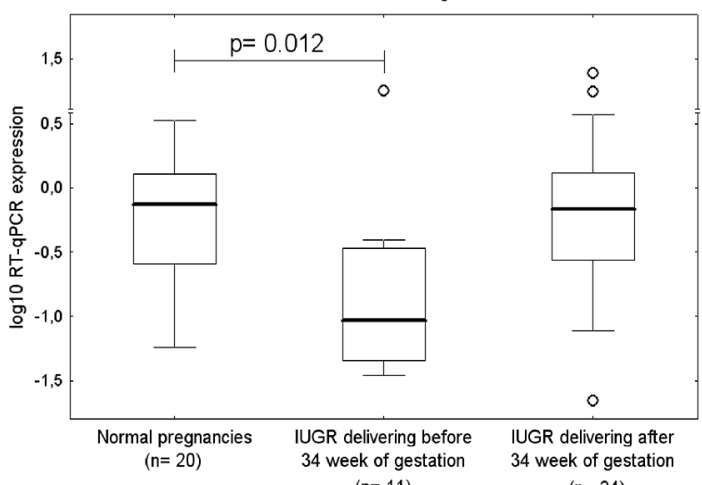

$(n=11)$
B

miR-125b-5p

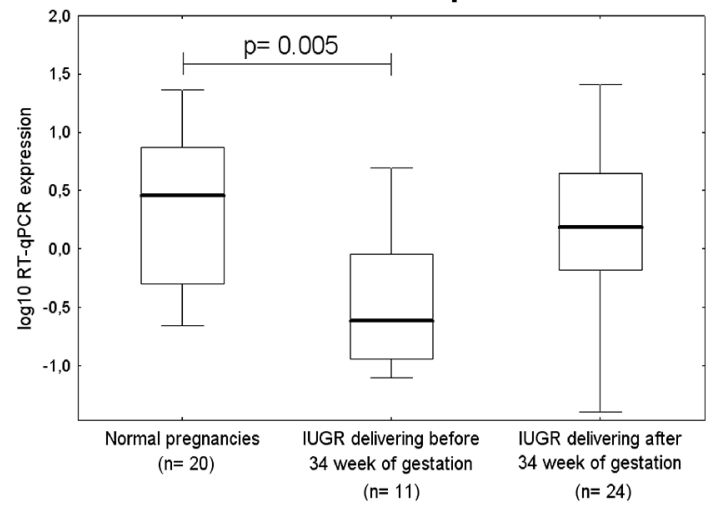

Fig 7. Down-regulation of miR-122-5p, miR-125b-5p, and miR-195-5p in IUGR. The expression of miR-122-5p (A), miR-125b-5p (B) and miR-195-5p (C) differs significantly between the control group and pregnancies affected with IUGR requiring the delivery before 34 week of gestation.

doi:10.1371/journal.pone.0138383.g007

Pregnancy-related complications such as gestational hypertension, preeclampsia and intrauterine growth restriction were observed to be associated with the same microRNA expression profile concerning mir-499a-5p. Nevertheless, the longer the pregnancy-related disorder lasted, the more extensive up-regulation of mir-499a-5p appeared. This suggests that the dysregulation of mir-499a-5p firstly appears during the onset of clinical symptoms of the disease, but could be intensified as a result of a sustainable development of compensatory mechanism when the disease persists for several weeks.

On the other hand, the dysregulation of miR-1-3p, which appears in preeclamptic pregnancies delivering after 34 weeks of gestation only, does not apparently drive the pathological process itself, but could be reflective of a long-term compensatory mechanism.

Limited data comparing mir-100-5p, miR-103a-3p, mir-122-5p, miR-125b-5p, miR-143-3p, miR-145-5p, miR-199a-5p, miR-221-3p, mir-342-3p, mir-499a-5p, and mir-574-3p levels between the groups of normal and complicated pregnancies are available.

With regard to miR-1-3p, our data are inconsistent with the studies of Zhu et al. [28] and Enquobahrie et al. [29] who found miR-1-3p to be significantly down-regulated in preeclamptic placentas.

The difference in the expression levels of microRNAs might be explained by different experimental approaches. Zhu et al. [28] performed the study mainly using tissue from the decidual side of the placenta (a collection of pooled tissue fragments derived from 10 randomly selected 
A

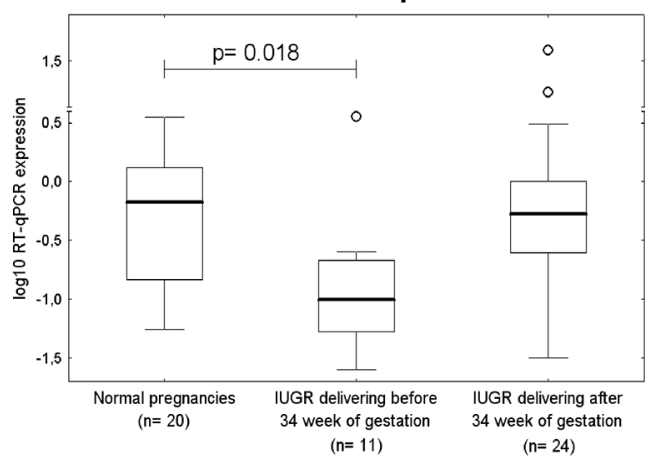

C

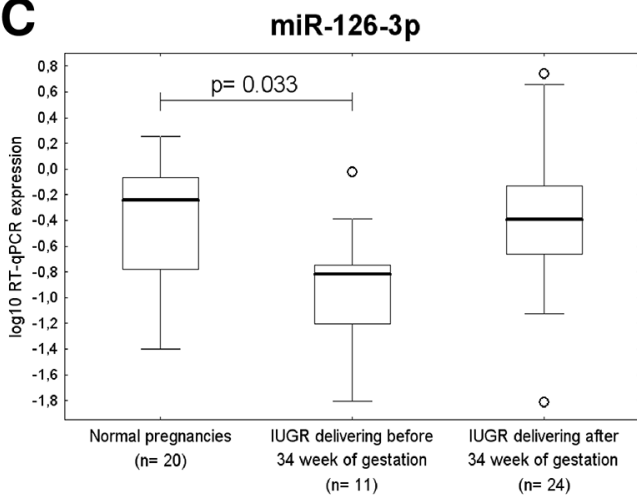

E

miR-199a-5p

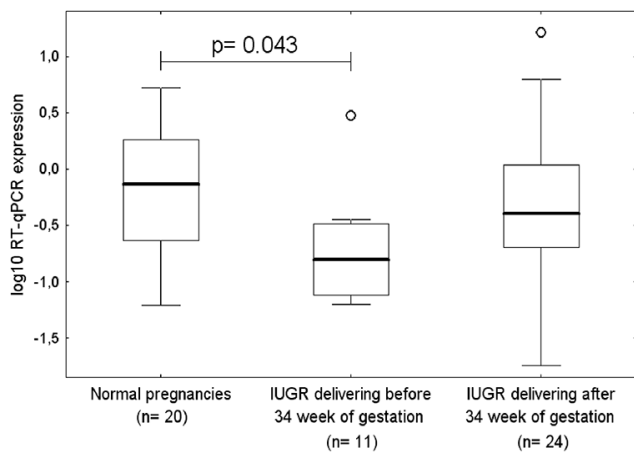

G

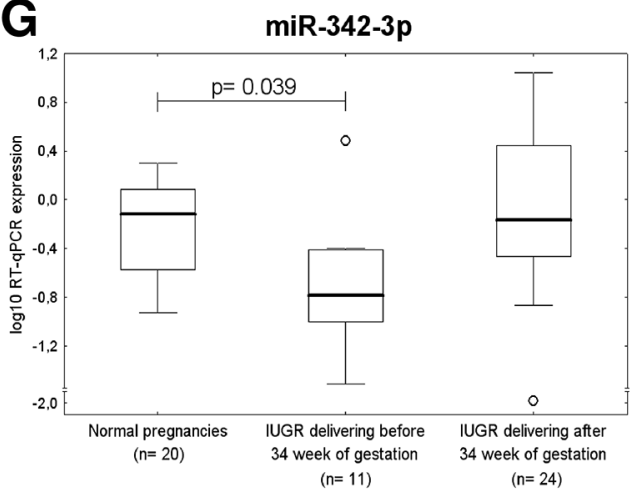

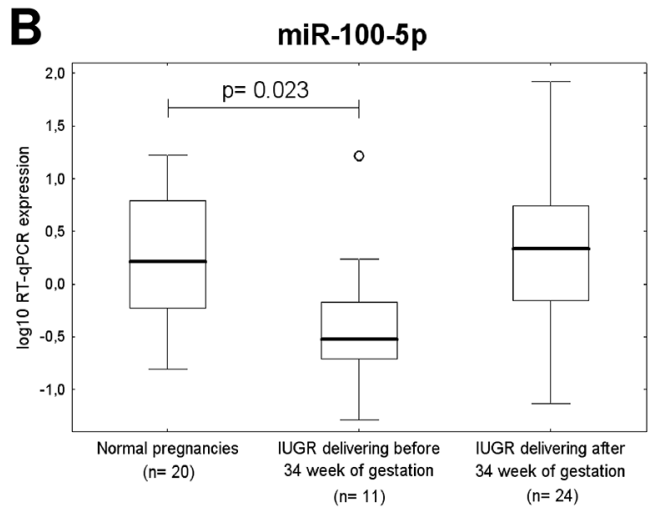

D miR-143-3p

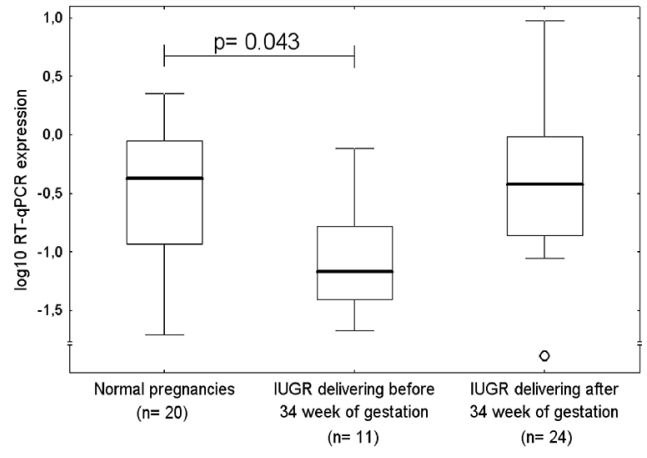

$\mathbf{F}$

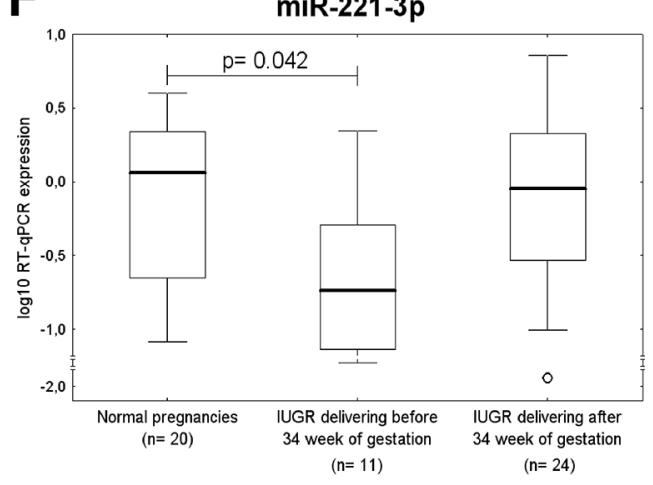

H

miR-574-3p

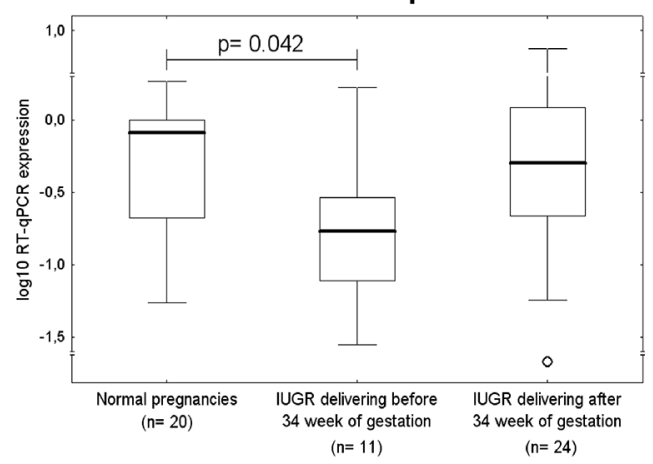


Fig 8. A trend to lower microRNA expression in IUGR pregnancies requiring the delivery before 34 week of gestation. MiR-16-5p (A), miR-100-5p (B), miR-126-3p (C), miR-143-3p (D), miR-199a-5p (E), miR-221-3p (F), miR-342-3p (G), and miR-574-3p (H) show a trend to down-regulation in placental tissues of IUGR pregnancies requiring the delivery before 34 week of gestation.

doi:10.1371/journal.pone.0138383.g008

sites on the placenta) using microarray and real-time RT-PCR, with the experimental data normalised to U6snRNA. Enquobahrie et al. [29] studied homogenates of placental tissues obtained from 16 various sites by a microarray miRNA profiling followed by validation analysis using real-time PCR with normalization to miR-525-5p. While, our group focused on the analysis of microRNA gene expression in the area of the central cotyledon and experimental real-time qRT-PCR data were normalized to RNU58A and U54, experimentally identified most stable endogenous controls in preeclamptic and IUGR placenta tissues.

Our study produced similar findings to Choi et al. [38], in which they reported no significant change in miR-26a-5p levels in severe preeclamptic pregnancies delivering after 34 weeks of gestation. Nevertheless, there is no study on preeclamptic and/or IUGR pregnancies delivering before 34 weeks of gestation.

Our data also confirmed data of Maccani et al. [30] who observed as well the difference in miR-16-5p placental expression between patients with fetal growth restricted foetuses (small for gestational age) and pregnancies with normal course of gestation. Maccani et al. [30] applied real-time RT-PCR analysis on a homogenized sample derived from 12 biopsies per placenta with normalization to RNU44. While Hu et al. [27] revealed up-regulation of miR-16-5p in severe preeclamptic placentas; our study indicated no statistical significance in miR-16-5p gene expression levels. Hu et al. [27] combined large-scale profiling of microRNA expression by microarray analysis with comprehensive quantitative analysis of miRNA expression by realtime RT-PCR relative to U6snRNA. The analyses were done on frozen chorionic tissue blocks from the central part of the placenta.

Diverse studies focused on placental expression of cardiovascular and cerebrovascular microRNAs in pregnancy-related complications brought dissimilar results. Hu et al. [27] and Yang et al. [45] reported significantly increased levels of mir-126-3p and miR-195-5p in preeclamptic placentas, however Bai et al. [33], Yan et al. [39], Hong et al. [40] and Xu et al. [44] identified miR-126-3p and miR-195-5p significantly downregulated in preeclamptic placentas. Our study indicated no statistical significance in mir-126-3p and miR-195-5p gene expression levels in placental tissues affected with preeclampsia, but in pregnancies complicated by IUGR that required the delivery before 34 weeks of gestation down-regulation of mir-126-3p and miR-195-5p was observed. Similarly, multiple studies [26-29, 34-36, 42, 44] demonstrated the up-regulation of miR-210-3p, miR-181a-5p, miR-21-5p and miR-17-5p or down-regulation of miR-210-3p, miR-181a-5p, miR-21-5p and miR-17-5p in preeclamptic placentas [31,38,44], which was not unfortunately observed in our independent study.

Several other microRNAs such as miR-155-5p, miR-20a-5p, miR-20b-5p, and miR-29a-3p were found up-regulated in placentas from preeclampsia compared to healthy term deliveries $[26,34,36,41,43]$ which is inconsistent with our finding.

It is important to note that only few similarities were observed. The discrepancies in microRNA placental expression may be attributed apart from no uniform way of data normalization to variability in other factors including patients' individual characteristics (mainly race and smoking), the sampling site within the placenta, sample handling and processing. Last but not least any finding needs to be validated in large-scale studies involving sufficient number of patients within particular studied groups. Proper normalization is a critical but often underappreciated aspect of quantitative gene expression analysis. The accuracy of microarrays and quantitative RT-PCR methods, most frequently used technologies for gene expression 
Table 3. A list of predicted or validated targets of appropriate microRNAs dysregulated in placental tissues of patients with pregnancy-related complications in relation to cardiovascular or cerebrovascular diseases using miRWalk, miRDB and miRTar databases.

\begin{tabular}{|c|c|c|c|c|}
\hline microRNA & miRWalk* & miRDB $^{+}$ & miRTar $^{+}$ & $\begin{array}{l}\text { Common targets of appropriate microRNA identified in mirWalk and miRDB or miRTar } \\
\text { databases }\end{array}$ \\
\hline miR-1-3p & 494 & 419 & 846 & $\begin{array}{l}69 \text { targets: ADAR, ALDH2, ANPEP, ARG1, BDNF, BMP7, CAPG, CAPN1, CCL2, CDK4, CEBPA, } \\
\text { CXCL1, EDN1, EGFR, F11R, F2, FABP3, FADS1, FLNA, FN1, FOXP1, G6PD, GATA4, GCH1, } \\
\text { GJA1, GNAI2, GSTO1, HADH, HDAC4, HMGCR, HMOX1, HSPA1A, HSPA4, HSPD1, IGF1, IL6, } \\
\text { IL8, KCNE1, KCNN4, KIF5B, LGALS1, LIMS1, LIPC, LRP1, MEF2A, MEX3C, MFN2, NOTCH3, } \\
\text { NR3C1, NRP1, PIM1, PROCR, PTPN1, PTPRF, SLC27A4, SP1, TCF7L2, THBS1, TIMP3, TLR4, } \\
\text { TPM1, TRPM6, TSHR, UNC93B1, VASP, VEGFA, YWHAZ }\end{array}$ \\
\hline $\operatorname{miR}-25 a-5 p$ & 375 & 515 & 181 & $\begin{array}{l}38 \text { targets: ABCA1, ADAM9, ADM, AHR, ARHGEF1, ATP1A1, ATP1A2, BCR, CA2, CDC6, CELSR1, } \\
\text { CFLAR, CTGF, CXADR, ESR1, FASN, FOXO3, GIT2, HSPA8, IL6, LIF, LRP6, NCEH1, NKX2-5, } \\
\text { PALLD, PCNA, PPIA, PTER, PTGS2, RB1, SARS, SLC12A2, SMAD1, TFAM, TGFBR2, TTN, } \\
\text { WNK1, ZNF652 }\end{array}$ \\
\hline $\begin{array}{l}\text { miR-103a- } \\
\text { 3p }\end{array}$ & 400 & 433 & 273 & $\begin{array}{l}23 \text { targets: APLN, ARF6, CA12, CAV1, CLOCK, CYP2C8, FGF2, FOXP1, FURIN, GPD1, ID2, INSIG1, } \\
\text { ITGA2, KIF5B, MAP4, MAPK8, MEX3C, MTHFR, NF1, PDE4D, PIK3R1, RORA, TGFBR3 }\end{array}$ \\
\hline miR-145-5p & 46 & 495 & 104 & $\begin{array}{l}20 \text { targets: ADAM17, AKR1B10, CDK4, CLOCK, CTGF, F11R, IGF1R, IRS1, IRS2, KLF5, MMP1, } \\
\text { MMP12, MMP14, POU5F1, PPP3CA, SERPINE1, SMAD3, STAT1, VEGFA, YES1 }\end{array}$ \\
\hline $\begin{array}{l}\text { miR-499a- } \\
5 p\end{array}$ & 7 & 249 & 3 & 0 target \\
\hline miR-16-5p & 458 & 1088 & 1157 & $\begin{array}{l}89 \text { targets: AGER, ALDH2, AMPD1, AP2B1, APLN, APLNR, APP, ARG2, ATXN2, CA12, CACNB2, } \\
\text { CD47, CLOCK, COL4A1, COMT, CPT1A, CUL4A, CYP27B1, EGFR, ENTPD1, F2, FASN, FDFT1, } \\
\text { FGF2, FGFR1, FLNA, G6PD, HMOX1, HSPA1A, HSPA1B, HSPA8, HSPD1, CHUK, IFNG, IGF2R, } \\
\text { ITGA2, JAK2, JUN, KCND3, KCNN4, KDR, KIF5B, LITAF, LRP6, MAP4, MAPK8, MERTK, MFN2, } \\
\text { MTHFD1L, MTHFR, NAMPT, NEUROG3, NF1, NFKB1, NISCH, NRP1, PDE4D, PGLYRP1, } \\
\text { PIK3R1, PIM1, PLAUR, POLB, PON2, PPP1R2, PRKAA1, PTGS2, RORA, RTN3, RTN4, SARS, } \\
\text { SERPINE2, SLC12A2, SLC27A4, SLC7A1, SMAD1, SMAD5, SP1, SYT4, TFPI, TGFBR3, TIMP3, } \\
\text { TNFRSF12A, TP53, VAMP8, VEGFA, VKORC1, WDTC1, WNT5A, XYLT1 }\end{array}$ \\
\hline miR-100-5p & 371 & 26 & 229 & $\begin{array}{l}17 \text { targets: APEX1, ATP1A2, ATP2A2, BMPR2, COL4A1, DDAH1, FLT1, FOXP1, HMGB1, ID1, } \\
\text { IGF1R, INSIG1, MMP13, MTOR, NLRP3, RB1, SMAD7 }\end{array}$ \\
\hline miR-122-5p & 121 & 187 & 237 & $\begin{array}{l}22 \text { targets: ADAM10, ADAM17, ATP1A2, CDK4, FOXP1, FSTL3, GSTM3, GYS1, HLA-DQA1, } \\
\text { HMOX1, IGF1R, KRT18, NFATC1, PHOX2A, PTPN1, RHOA, SLC7A1, SLC9A1, SOCS1, SOX2, } \\
\text { SRF, TRIB1 }\end{array}$ \\
\hline $\begin{array}{l}\text { miR-125b- } \\
5 p\end{array}$ & 393 & 476 & 340 & $\begin{array}{l}35 \text { targets: ADD2, ADM, ASIC1, ATP5B, ATXN1, BMPR1B, CDKN2A, CEBPA, CYP1A1, ENPEP, } \\
\text { ERBB3, ESRRA, HSPA1B, HSPD1, ID1, ID2, IGF2, IL1RN, IL6, ITGB3, LIF, MAPK14, MMP13, } \\
\text { PARP1, PTGES, S100A8, SCARB2, SLC16A4, SLC7A1, STAT3, TBC1D1, TOR2A, TP53, VDR, } \\
\text { WNK1 }\end{array}$ \\
\hline miR-126-3p & 409 & 2 & 32 & 10 targets: ADAM9, CXCL12, IGFBP2, IRS1, KRAS, MERTK, PGR, SOX2, VCAM1, VEGFA \\
\hline miR-143-3p & 37 & 375 & 20 & 6 targets: AKT1, KRAS, MAPK7, MMP13, PTGS2, SERPINE1 \\
\hline miR-195-5p & 374 & 1089 & 39 & $\begin{array}{l}36 \text { targets: AGER, APLN, APLNR, ATXN2, BDNF, BVES, CD47, CDK4, COMT, ENTPD1, FASN, } \\
\text { FDFT1, FGF2, FGFR1, G6PD, HSPA1B, CHUK, JAK2, LITAF, LRP6, MAP4, MAPK9, MFN2, } \\
\text { MTHFR, NEUROG3, NF1, PIK3R1, PPP1R2, PRKAA1, RORA, RTN3, SLC12A2, SMAD3, SYT4, } \\
\text { VEGFA, WDTC1 }\end{array}$ \\
\hline $\begin{array}{l}\operatorname{miR}-199 a- \\
5 p\end{array}$ & 29 & 334 & 24 & 7 targets: CAV1, CD44, EDN1, ERBB2, HIF1A, LIF, SIRT1 \\
\hline miR-221-3p & 416 & 316 & 253 & $\begin{array}{l}31 \text { targets: ADD1, ATP2A2, ATXN1, BRAP, CD4, CDKN1C, CTNNB1, CXCL12, DDAH1, ESR1, } \\
\text { FLNA, FOXO3, ICAM1, INSIG1, ITGB3, KIT, LIMS1, LRP6, MFN2, PIK3R1, RHOA, SELE, SLC6A9, } \\
\text { SOD2, TIMP3, TNFSF10, TP53, TRPC3, TUB, YY1, ZNF652 }\end{array}$ \\
\hline miR-342-3p & 360 & 274 & 83 & $\begin{array}{l}16 \text { targets: BMP7, CXADR, GJA1, GSTA4, HNRNPC, INSIG1, ITGAM, JUN, LRP8, MAPT, NOS1AP, } \\
\text { OSBPL8, PTPRC, PTPRN, SLC7A1, SOD2 }\end{array}$ \\
\hline miR-574-3p & 358 & 16 & 2 & 1 target: RXRA \\
\hline
\end{tabular}

* number of verified targets in relation to human disease onthology

${ }^{+}$number of predicted targets

MiRDB and miRTar databases were used to predict targets of those microRNAs that have been found to be dysregulated in placental tissues of patients with pregnancy-related complications. miRWalk database and the Validated Targets module were used to provide information on experimentally verified interaction between appropriate microRNA and specific genes on human disease ontologies such as heart disease, myocardial infarction, congestive heart failure, vascular disease, cerebral infarction, hypertension, obesity, atherosclerosis, hypercholesterolemia, diabetic angiopathy, insulin resistance and diabetes.

doi:10.1371/journal.pone.0138383.t003 
profiling, however, is critically dependent on proper normalization of the data in as much as inappropriate normalization of qRT-PCR data can lead to incorrect conclusions [137, 138, 139].

Moreover, the power of the study for particular cases and 2 confidence levels ( $80 \%$ and 90\%) together with minimal calculated number of subjects involved in the study should be calculated. The conclusion that expression levels of microRNAs in placental tissue differentiated between healthy pregnant women and pregnancy-related complications should not be done until the base of this statistical analysis. Determining the optimal sample size for a study assures an adequate power to detect statistical significance. Hence, it is a critical step in the design of a planned research protocol. Using too many participants in a study is expensive and exposes more number of subjects to procedure. Similarly, if study is underpowered, it will be statistically inconclusive and may make the whole protocol a failure [140].

\section{Conclusions}

In conclusion, epigenetic changes induced by pregnancy-related complications in placental tissue may cause later onset of cardiovascular and cerebrovascular diseases in offspring.

Placental functions influence placenta itself, as well as the mother and the developing fetus, establishing a likely role in developmental programming of the fetus [141]. Alterations in blood vessel formation during placental development has the potential to reduce blood flow, leading to reduced nutrient delivery and an environment of fetal undernutrition. Fetal nutrition, or the supply of metabolic substrates delivered for growth and development, contributes to immediate, intermediate, and long-term health [142]. Immediate health consequences include intrauterine growth restriction and low birthweight. Childhood obesity, hypertension, and diabetes are the most common intermediate and long-term health consequences of fetal undernutrition [143]. Some authors postulate that early fetal and infant environment is strongly predictive for the risk of cardiovascular and cerebrovascular diseases later in life [143147].

The main pathways by which preeclampsia or pregnancy-related complications serve to modify vascular risk would appear to be hypoxia, antiangiogenesis, endothelial dysfunction and immune modifications. These pathways individually, synergistically, or cumulatively appear to alter the epigenetic potential of placenta itself including microRNA expression profile. And so the exposition to a preeclampsia or pregnancy-related complication environment in utero leads to altered phenotype after birth [147].

\section{Author Contributions}

Conceived and designed the experiments: IH KK. Performed the experiments: KK LH. Analyzed the data: IH KK LH LK. Contributed reagents/materials/analysis tools: KK LH LK. Wrote the paper: IH KK LH LK.

\section{References}

1. WHO. Geographic variation in the incidence of hypertension in pregnancy. World Health Organization International Collaborative Study of Hypertensive Disorders of Pregnancy. Am J Obstet Gynecol. 1988; 158(1): 80-83. PMID: 2962500

2. Bamfo JE, Odibo AO. Diagnosis and management of fetal growth restriction. J Pregnancy. 2011; 640715. doi: 10.1155/2011/640715 PMID: 21547092

3. ACOG practice bulletin. Diagnosis and management of preeclampsia and eclampsia. Obstet Gynecol. 2002; 99(1): 159-167. PMID: 16175681 
4. Khong TY, De Wolf F, Robertson WB, Brosens I. Inadequate maternal vascular response to placentation in pregnancies complicated by pre-eclampsia and by small-for-gestational age infants. $\mathrm{Br} \mathrm{J}$ Obstet Gynaecol. 1986; 93(10): 1049-1059. PMID: 3790464

5. Khan KS, Wojdyla D, Say L, Gülmezoglu AM, Van Look PF. WHO analysis of causes of maternal death: a systematic review. Lancet. 2006; 367(9516): 1066-1074. PMID: 16581405

6. Miko E, Meggyes M, Bogar B, Schmitz N, Barakonyi A, Varnagy A, et al. Involvement of Galectin-9/ TIM-3 pathway in the systemic inflammatory response in early-onset preeclampsia. PLoS One. 2013; 8(8): e71811. doi: 10.1371/journal.pone.0071811 PMID: 23936526

7. Garovic VD, Hayman SR. Hypertension in pregnancy: an emerging risk factor for cardiovascular disease. Nat Clin Pract Nephrol. 2007; 3(11): 613-622. PMID: 17957198

8. Libby G, Murphy DJ, McEwan NF, Greene SA, Forsyth JS, Chien PW, et al. Pre-eclampsia and the later development of type 2 diabetes in mothers and their children: an intergenerational study from the Walker cohort. Diabetologia. 2007; 50(3): 523-530. PMID: 17187247

9. Männistö $T$, Mendola $P$, Vääräsmäki $M$, Järvelin $M R$, Hartikainen $A L$, Pouta $A$, et al. Elevated blood pressure in pregnancy and subsequent chronic disease risk. Circulation. 2013; 127(6): 681-690. doi: 10.1161/CIRCULATIONAHA.112.128751 PMID: 23401113

10. Bellamy L, Casas JP, Hingorani AD, Williams DJ. Pre-eclampsia and risk of cardiovascular disease and cancer in later life: systematic review and meta-analysis. BMJ. 2007; 335(7627):974. PMID: 17975258

11. Craici IM, Wagner SJ, Hayman SR, Garovic VD. Pre-eclamptic pregnancies: an opportunity to identify women at risk for future cardiovascular disease. Womens Health (Lond Engl). 2008; 4(2): 133-135.

12. Haukkamaa L, Moilanen L, Kattainen $A$, Luoto $R$, Kahonen $M$, Leinonen $M$, et al. Pre-eclampsia is a risk factor of carotid artery atherosclerosis. Cerebrovasc Dis. 2009; 27(6): 599-607. doi: 10.1159/ 000216834 PMID: 19407443

13. Lykke JA, Langhoff-Roos J, Sibai BM, Funai EF, Triche EW, Paidas MJ. Hypertensive pregnancy disorders and subsequent cardiovascular morbidity and type 2 diabetes mellitus in the mother. Hypertension. 2009; 53(6): 944-951. doi: 10.1161/HYPERTENSIONAHA.109.130765 PMID: 19433776

14. Berks D, Hoedjes M, Raat H, Duvekot JJ, Steegers EA, Habbema JD. Risk of cardiovascular disease after pre-eclampsia and the effect of lifestyle interventions: a literature-based study. BJOG. 2013; 120 (8): 924-931. doi: 10.1111/1471-0528.12191 PMID: 23530583

15. McDonald SD, Ray J, Teo K, Jung H, Salehian O, Yusuf S, et al. Measures of cardiovascular risk and subclinical atherosclerosis in a cohort of women with a remote history of preeclampsia. Atherosclerosis. 2013; 229(1): 234-239. doi: 10.1016/j.atherosclerosis.2013.04.020 PMID: 23664201

16. Borna S, Neamatipoor E, Radman N. Risk of coronary artery disease in women with history of pregnancies complicated by preeclampsia and LBW. J Matern Fetal Neonatal Med. 2012; 25(7): 11141116. doi: 10.3109/14767058.2011.624218 PMID: 21923611

17. Davis EF, Lazdam M, Lewandowski AJ, Worton SA, Kelly B, Kenworthy Y, et al. Cardiovascular risk factors in children and young adults born to preeclamptic pregnancies: a systematic review. Pediatrics. 2012; 129(6): e1552-1561. doi: 10.1542/peds.2011-3093 PMID: 22614768

18. Tappia PS, Gabriel CA. Role of nutrition in the development of the fetal cardiovascular system. Expert Rev Cardiovasc Ther. 2006; 4(2): 211-225. PMID: 16509817

19. Esplin MS, Fausett MB, Fraser A, Kerber R, Mineau G, Carrillo J, et al. Paternal and maternal components of the predisposition to preeclampsia. N Engl J Med. 2001; 344(12): 867-872. PMID: 11259719

20. Skjaerven R, Vatten LJ, Wilcox AJ, Rønning T, Irgens LM, Lie RT. Recurrence of pre-eclampsia across generations: exploring fetal and maternal genetic components in a population based cohort. BMJ. 2005; 331(7521): 877. PMID: 16169871

21. Anderson $\mathrm{CM}$. Preeclampsia: exposing future cardiovascular risk in mothers and their children. $J$ Obstet Gynecol Neonatal Nurs. 2007; 36(1): 3-8. PMID: 17238941

22. Lai EC. Micro RNAs are complementary to $3^{\prime}$ UTR sequence motifs that mediate negative post-transcriptional regulation. Nat Genet. 2002; 30(4): 363-364. PMID: 11896390

23. Bartel DP. MicroRNAs: genomics, biogenesis, mechanism, and function. Cell. 2004; 116(2): $281-$ 297. PMID: 14744438

24. Calin GA, Croce CM. MicroRNAs and chromosomal abnormalities in cancer cells. Oncogene. 2005; 25(46): 6202-6210.

25. Rosenfeld N, Aharonov R, Meiri E, Rosenwald S, Spector Y, Zepeniuk M, et al. MicroRNAs accurately identify cancer tissue origin. Nat Biotechnol. 2008; 26(4): 462-469. doi: 10.1038/nbt1392 PMID: 18362881 
26. Pineles BL, Romero R, Montenegro D, Tarca AL, Han YM, Kim YM, et al. Distinct subsets of microRNAs are expressed differentially in the human placentas of patients with preeclampsia. Am J Obstet Gynecol. 2007; 196(3): 261.e261-266.

27. Hu Y, Li P, Hao S, Liu L, Zhao J, Hou Y. Differential expression of microRNAs in the placentae of Chinese patients with severe pre-eclampsia. Clin Chem Lab Med. 2009; 47(8): 923-929. doi: 10.1515/ CCLM.2009.228 PMID: 19642860

28. Zhu XM, Han T, Sargent IL, Yin GW, Yao YQ. Differential expression profile of microRNAs in human placentas from preeclamptic pregnancies vs normal pregnancies. Am J Obstet Gynecol. 2009; 200 (6): 661.e661-667.

29. Enquobahrie DA, Abetew DF, Sorensen TK, Willoughby D, Chidambaram K, Williams MA. Placental microRNA expression in pregnancies complicated by preeclampsia. Am J Obstet Gynecol. 2011; 204 (2): 178.e112-121.

30. Maccani MA, Padbury JF, Marsit CJ. miR-16 and miR-21 expression in the placenta is associated with fetal growth. PLoS One. 2011; 6(6): e21210. doi: 10.1371/journal.pone.0021210 PMID: 21698265

31. Mayor-Lynn K, Toloubeydokhti T, Cruz AC, Chegini N. Expression profile of microRNAs and mRNAs in human placentas from pregnancies complicated by preeclampsia and preterm labor. Reprod Sci. 2011; 18(1): 46-56. doi: 10.1177/1933719110374115 PMID: 21079238

32. Noack F, Ribbat-Idel J, Thorns C, Chiriac A, Axt-Fliedner R, Diedrich K, et al. miRNA expression profiling in formalin-fixed and paraffin-embedded placental tissue samples from pregnancies with severe preeclampsia. J Perinat Med. 2011; 39(3): 267-271. doi: 10.1515/JPM.2011.012 PMID: 21309633

33. Bai Y, Yang W, Yang HX, Liao Q, Ye G, Fu G, et al. Downregulated miR-195 detected in preeclamptic placenta affects trophoblast cell invasion via modulating ActRIIA expression. PLoS One. 2012; 7(6): e38875. doi: 10.1371/journal.pone.0038875 PMID: 22723898

34. Ishibashi O, Ohkuchi A, Ali MM, Kurashina R, Luo SS, Ishikawa T, et al. Hydroxysteroid (17- $\beta$ ) dehydrogenase 1 is dysregulated by miR-210 and miR-518c that are aberrantly expressed in preeclamptic placentas: a novel marker for predicting preeclampsia. Hypertension. 2012; 59(2): 265-273. doi: 10. 1161/HYPERTENSIONAHA.111.180232 PMID: 22203747

35. Muralimanoharan S, Maloyan A, Mele J, Guo C, Myatt LG, Myatt L. MIR-210 modulates mitochondrial respiration in placenta with preeclampsia. Placenta. 2012; 33(10): 816-823. doi: 10.1016/j.placenta. 2012.07.002 PMID: 22840297

36. Wang W, Feng L, Zhang H, Hachy S, Satohisa S, Laurent LC, et al. Preeclampsia up-regulates angiogenesis-associated microRNA (i.e., miR-17, -20a, and -20b) that target ephrin-B2 and EPHB4 in human placenta. J Clin Endocrinol Metab. 2012; 97(6): E1051-9. doi: 10.1210/jc.2011-3131 PMID: 22438230

37. Higashijima A, Miura K, Mishima H, Kinoshita A, Jo O, Abe S, et al. Characterization of placenta-specific microRNAs in fetal growth restriction pregnancy. Prenat Diagn. 2013; 33(3): 214-222. doi: 10. 1002/pd.4045 PMID: 23354729

38. Choi SY, Yun J, Lee OJ, Han HS, Yeo MK, Lee MA, et al. MicroRNA expression profiles in placenta with severe preeclampsia using a PNA-based microarray. Placenta. 2013; 34(9): 799-804. doi: 10. 1016/j.placenta.2013.06.006 PMID: 23830491

39. Yan T, Liu Y, Cui K, Hu B, Wang F, Zou L. MicroRNA-126 regulates EPCs function: implications for a role of miR-126 in preeclampsia. J Cell Biochem. 2013; 114(9): 2148-2159. doi: 10.1002/jcb.24563 PMID: 23553946

40. Hong F, Li Y, Xu Y. Decreased placental miR-126 expression and vascular endothelial growth factor levels in patients with pre-eclampsia. J Int Med Res. 2014; 42(6): 1243-1251. doi: 10.1177/ 0300060514540627 PMID: 25341970

41. Li X, Li C, Dong X, Gou W. MicroRNA-155 inhibits migration of trophoblast cells and contributes to the pathogenesis of severe preeclampsia by regulating endothelial nitric oxide synthase. Mol Med Rep. 2014; 10(1): 550-554. doi: 10.3892/mmr.2014.2214 PMID: 24806148

42. Luo R, Shao X, Xu P, Liu Y, Wang Y, Zhao Y, et al. MicroRNA-210 contributes to preeclampsia by downregulating potassium channel modulatory factor 1 . Hypertension. 2014; 64(4): 839-845. doi: 10. 1161/HYPERTENSIONAHA.114.03530 PMID: 24980667

43. Wang $\mathrm{Y}$, Zhang $\mathrm{Y}$, Wang $\mathrm{H}$, Wang J, Zhang $\mathrm{Y}$, Wang $\mathrm{Y}$, et al. Aberrantly up-regulated miR-20a in preeclampsic placenta compromised the proliferative and invasive behaviors of trophoblast cells by targeting forkhead box protein A1. Int J Biol Sci. 2014; 10(9): 973-982. doi: 10.7150/ijbs.9088 PMID: 25210495

44. Xu P, Zhao Y, Liu M, Wang Y, Wang H, Li YX, et al. Variations of microRNAs in human placentas and plasma from preeclamptic pregnancy. Hypertension. 2014; 63(6): 1276-1284. doi: 10.1161/ HYPERTENSIONAHA.113.02647 PMID: 24664294 
45. Yang S, Li H, Ge Q, Guo L, Chen F. Deregulated microRNA species in the plasma and placenta of patients with preeclampsia. Mol Med Rep. 2015; 12(1): 527-534. doi: 10.3892/mmr.2015.3414 PMID: 25738738

46. He A, Zhu L, Gupta N, Chang Y, Fang F. Overexpression of micro ribonucleic acid 29, highly up-regulated in diabetic rats, leads to insulin resistance in 3T3-L1 adipocytes. Mol Endocrinol. 2007; 21: 2785-2794. PMID: 17652184

47. Elmén J, Lindow M, Silahtaroglu A, Bak M, Christensen M, Lind-Thomsen A, et al. Antagonism of microRNA-122 in mice by systemically administered LNA-antimiR leads to up-regulation of a large set of predicted target mRNAs in the liver. Nucleic Acids Res. 2008; 36(4): 1153-1162. PMID: 18158304

48. Elmén J, Lindow $M$, Schütz $S$, Lawrence M, Petri A, Obad S, et al. LNA-mediated microRNA silencing in non-human primates. Nature. 2008; 452(7189): 896-899. doi: 10.1038/nature06783 PMID: 18368051

49. Fish JE, Santoro MM, Morton SU, Yu S, Yeh RF, Wythe JD, et al. miR-126 regulates angiogenic signaling and vascular integrity. Dev Cell. 2008; 15: 272-284. doi: 10.1016/j.devcel.2008.07.008 PMID: 18694566

50. Wang S, Aurora AB, Johnson BA, Qi X, McAnallz J, Hill JA, et al. The endothelial-specific microRNA miR-126 governs vascular integrity and angiogenesis. Dev Cell. 2008; 15: 261-271. doi: 10.1016/j. devcel.2008.07.002 PMID: 18694565

51. Chen T, Huang Z, Wang L, Wang Y, Wu F, Meng S, et al. MicroRNA-125a-5p partly regulates the inflammatory response, lipid uptake, and ORP9 expression in oxLDL-stimulated monocytes/macrophages. Cardiovasc Res. 2009; 83: 131-139. doi: 10.1093/cvr/cvp121 PMID: 19377067

52. Marquart TJ, Allen RM, Ory DS, Baldan A. miR-33 links SREBP-2 induction to repression of sterol transporters. Proc Natl Acad Sci U.S.A. 2010; 107: 12228-12232. doi: 10.1073/pnas.1005191107 PMID: 20566875

53. Najafi-Shoushtari SH, Kristo F, Li Y, Shioda T, Cohen DE, Gerszten RE, et al. MicroRNA-33 and the SREBP host genes cooperate to control cholesterol homeostasis. Science. 2010; 328: 1566-1569 doi: 10.1126/science.1189123 PMID: 20466882

54. Rayner KJ, Suarez Y, Davalos A, Parathath S, Fitzgerald ML, Tamehiro N, et al. Mir- 33 contributes to the regulation of cholesterol homeostasis. Science. 2010; 328: 1570-1573. doi: 10.1126/science. 1189862 PMID: 20466885

55. Zampetaki A, KiechI S, Drozdov I, Willeit P, Mayr U, Prokopi M, et al. Plasma microRNA profiling reveals loss of endothelial miR-126 and other microRNAs in type 2 diabetes. Circ Res. 2010; 107(6): 810-817. doi: 10.1161/CIRCRESAHA.110.226357 PMID: 20651284

56. Zhao H, Guan J, Lee HM, Sui Y, He L, Siu JJ, et al. Up-regulated pancreatic tissue microRNA-375 associates with human type 2 diabetes through $\beta$-cell deficit and islet amyloid deposition. Pancreas. 2010; 39: 843-846. doi: 10.1097/MPA.0b013e3181d12613 PMID: 20467341

57. Kida K, Nakajima M, Mohri T, Oda Y, Takagi S, Fukami T, et al. PPARa is regulated by miR-21 and miR-27b in human liver. Pharm Res. 2011; 28: 2467-2476. doi: 10.1007/s11095-011-0473-y PMID: 21562928

58. Pullen TJ, da Silva Xavier G, Kelsey G, Rutter GA. miR-29a and miR-29b contribute to pancreatic $\beta$ cell-specific silencing of monocarboxylate transporter 1 (Mct1). Mol Cell Biol. 2011; 31: 3182-3194. doi: 10.1128/MCB.01433-10 PMID: 21646425

59. Rayner KJ, Esau CC, Hussain FN, McDaniel AL, Marshall SM, van Gils JM, et al. Inhibition of miR$33 \mathrm{a} / \mathrm{b}$ in non-human primates raises plasma HDL and lowers VLDL triglycerides. Nature. $2011 ; 478$ (7369): 404-407. doi: 10.1038/nature10486 PMID: 22012398

60. Ryu HS, Park SY, Ma D, Zhang J, Lee W. The induction of microRNA targeting IRS-1 is involved in the development of insulin resistance under conditions of mitochondrial dysfunction in hepatocytes. PLoS ONE. 2011; 6: e17343. doi: 10.1371/journal.pone.0017343 PMID: 21464990

61. Yang K, He YS, Wang XQ, Lu L, Chen QJ, Liu J, et al. Mir-146a inhibits oxidized low-density lipoprotein-induced lipid accumulation and inflammatory response via targeting Toll-like receptor 4. FEBS Lett. 2011; 585: 854-860. doi: 10.1016/j.febslet.2011.02.009 PMID: 21329689

62. Zhong D, Zhang Y, Zeng YJ, Gao M, Wu GZ, Hu CJ, et al. MicroRNA-613 represses lipogenesis in HepG2 cells by downregulating LXRa. Lipids Health Dis. 2013; 12: 32. doi: 10.1186/1476-511X-12-32 PMID: 23496987

63. Zhong D, Huang G, Zhang $Y$, Zeng $Y, X u$ Z, Zhao $Y$, et al. MicroRNA-1 and microRNA-206 suppress LXRa-induced lipogenesis in hepatocytes. Cell Signaling. 2013; 25: 1429-1437.

64. van Rooij E, Sutherland LB, Qi X, Richardson JA, Hill J, Olson EN. Control of stress-dependent cardiac growth and gene expression bz a microRNA. Science. 2007; 316: 575-579. PMID: 17379774 
65. Thum T, Gross C, Fiedler J, Fischer T, Kissler S, Bussen M, et al. MicroRNA-21 contributes to myocardial disease by stimulating MAP kinase signalling in fibroblasts. Nature. 2008; 456(7224): 980 984. doi: 10.1038/nature07511 PMID: 19043405

66. Callis TE, Pandya K, Seok HY, Tang RH, Tatsuguchi M, Huang ZP, et al. MicroRNA-208a is a regulator of cardiac hypertrophy and conduction in mice. J Clin Invest. 2009; 119(9): 2772-2786. doi: 10. 1172/JCI36154 PMID: 19726871

67. Elia L, Quintavalle M, Zhang J, Contu R, Cossu L, Latronico MV, et al. The knockout of miR-143 and -145 alters smooth muscle cell maintenance and vascular homeostasis in mice: correlates with human disease. Cell Death Differ. 2009; 16(12): 1590-1598. doi: 10.1038/cdd.2009.153 PMID: 19816508

68. Xin M, Small EM, Sutherland LB, Qi X, McAnally J, Plato CF, et al. MicroRNAs miR-143 and miR-145 modulate cytoskeletal dynamics and responsiveness of smooth muscle cells Indry. Gens Dev. 2009; 23: 2166-2178.

69. Li S, Zhu J, Zhang W, Chen Y, Zhang K, Popescu LM. Signature microRNA expression profile of essential hypertension and its novel link to human cytomegalovirus infection. Circulation. 2011; 124 (2): 175-184. doi: 10.1161/CIRCULATIONAHA.110.012237 PMID: 21690488

70. Norata GD, Pinna C, Yappella F, ELia L, Sala A, Condorelli G, et al. (2012) MicroRNA 143-145 deficiency impairs vascular function. Int J Immunopathol Pharmacol. 2012; 25: 467-474. PMID: 22697078

71. O'Connell RM, Taganov KD, Boldin MP, Cheng G, Baltimore D. MicroRNA-155 is induced during the macrophage inflammatory response. Proc Natl Acad Sci U.S.A. 2007; 104: 1604-1609. PMID: 17242365

72. Harris TA, Yamakuchi M, Ferlito M, Mendell JT, Lowenstein CJ. MicroRNA-126 regulates endothelial expression of vascular cell adhesion molecule 1. Proc Natl Acad Sci U.S.A. 2008; 105: 1516-1521. doi: 10.1073/pnas.0707493105 PMID: 18227515

73. Wang YS, Wang HY, Liao YC, Tsai PC, Chen KC, Cheng HY, et al. MicroRNA-195 regulates vascular smooth muscle cell phenotype and prevents neointimal formation. Cardiovasc Res. 2012; 95: 517526. doi: 10.1093/cvr/cvs223 PMID: 22802111

74. Zampetaki A, Kiechl S, Drozdov I, Willeit P, Mayr U, Prokopi M, et al. Plasma microRNA profiling reveals loss of endothelial miR-126 and other microRNAs in type 2 diabetes. Circ Res. 2010; 107(6): 810-817. doi: 10.1161/CIRCRESAHA.110.226357 PMID: 20651284

75. Kong L, Zhu J, Han W, Jiang X, Xu M, Zhao Y, et al. Significance of serum microRNAs in pre-diabetes and newly diagnosed type 2 diabetes: a clinical study. Acta Diabetol. 2011; 48(1): 61-69. doi: 10. 1007/s00592-010-0226-0 PMID: 20857148

76. Ji R, Cheng Y, Yue J, Yang J, Liu X, Chen H, et al. MicroRNA expression signature and antisensemediated depletion reveal an essential role of microRNA in vascular neointimal lesion formation. Circ Res. 2007; 100: 1579-1588. PMID: 17478730

77. Hartus TA, Yamakuchi M, Ferlito M, Mendell JT, Lowenstein CJ.MicroRNA-126 regulates endothelial expression of vascular cell adhesion molecule 1. Proc Natl Acad Sci U.S.A. 2008; 105: 1516-1521. doi: 10.1073/pnas.0707493105 PMID: 18227515

78. Cordes KR, Sheehy NT, White MP, Berry EC, Morton SU, Muth AN, et al. miR-145 and miR-143 regulate smooth Musile cell fate and plasticity. Nature. 2009; 460: 705-710. doi: 10.1038/nature08195 PMID: 19578358

79. Raitoharju E, Lyytikäinen LP, Levula M, Oksala N, Mennander A, Tarkka M, et al. miR-21, miR-210, $\mathrm{miR}-34 \mathrm{a}$, and $\mathrm{miR}-146 \mathrm{a} / \mathrm{b}$ are up-regulated in human atherosclerotic plaques in the Tampere Vascular Study. Atherosclerosis. 2011; 219(1): 211-217. doi: 10.1016/j.atherosclerosis.2011.07.020 PMID: 21820659

80. Rayner KJ, Moore KJ. The plaque "micro" environment: microRNAs control the risk and the development of atherosclerosis. Curr Atheroscler Rep. 2012; 14: 413-421. doi: 10.1007/s11883-012-0272-X PMID: 22847770

81. Yhu J, Chen T, Yang L, Li Z, Wong MM, Zheng X, et al. Regulation of microRNA-155 in atherosclerotic inflammatory responses by targeting MAP3K10. PLoS ONE. 2012; 7: e46551. doi: 10.1371/journal. pone.0046551 PMID: 23189122

82. Wei $Y$, Nazari-Jahantigh M, Neth $P$, Weber $C$, Schober A. MicroRNA-126, -145, and -155: a therapeutic triad in atherosclerosis? Arterioscler Thromb Vasc Biol. 2013; 33: 449-454. doi: 10.1161/ ATVBAHA.112.300279 PMID: 23324496

83. Poliseno L, Tuccoli A, Mariani L, Evangelista M, Citti L, Woods K, et al. MicroRNAs modulace the angiogenic properties of HUVECs. Blood. 2006; 108: 3068-3071. PMID: 16849646 
84. Doebele C, Bonauer A, Fischer A, Scholz A, Reiss Y, Urbich C, et al. Members of the microRNA-1792 cluster exhibit a cell-intrinsic antiangiogenic function in endothelial cells. Blood. 2010; 115(23): 4944-4950. doi: 10.1182/blood-2010-01-264812 PMID: 20299512

85. Grundmann S, Hans FP, Kinniry S, Heinke J, Helbing T, Bluhm F, et al. MicroRNA-100 regulates neovascularization by suppression of mammalian target of rapamycin in endothelial and vascular smooth muscle cells. Circulation. 2011; 123(9): 999-1009. doi: 10.1161/CIRCULATIONAHA.110.000323 PMID: 21339483

86. Cheng Y, Liu X, Yang J, Lin Y, Xu DZ, Lu Q, et al. MicroRNA-145, a novel smooth muscle cell phenotzpic marker and modulátor, controls vascular neointimal lesion formation. Circ Res. 2009; 105 : 158-166. doi: 10.1161/CIRCRESAHA.109.197517 PMID: 19542014

87. Xin M, Small EM, Sutherland LB, Qi X, McAnally J, Plato CF, et al. MicroRNAs miR-143 and miR-145 modulate cytoskeletal dynamics and responsiveness of smooth muscle cells Indry. Gens Dev. 2009; 23: 2166-2178.

88. Zernecke A, Bidzhekov K, Noels H, Shagdarsuren E, Gan L, Denecke B, et al. Delivery of microRNA126 by apoptotic bodies induces CXCL12-dependent vascular protection. Sci Signal. 2009; 2(100): ra81. doi: 10.1126/scisignal.2000610 PMID: 19996457

89. Fichtlscherer S, De Rosa S, Fox H, Schwietz T, Fischer A, Liebetrau C, et al. Circulating microRNAs in patients with coronary artery disease. Circ Res. 2010; 107(5): 677-684. doi: 10.1161/ CIRCRESAHA.109.215566 PMID: 20595655

90. Liu X, Cheng Y, Yang J, Xu L, Zhang C. Cell-specific effects of miR-221/222 in vessels: molecular mechanism and therapeutic application. J Mol Cell Cardiol. 2012; 52: 245-255. doi: 10.1016/j.yjmcc. 2011.11.008 PMID: 22138289

91. Wang YS, Wang HY, Liao YC, Tsai PC, Chen KC, Cheng HY, et al. MicroRNA-195 regulates vascular smooth muscle cell phenotype and prevents neointimal formation. Cardiovasc Res. 2012; 95: 517526. doi: 10.1093/cvr/cvs223 PMID: 22802111

92. Olson EN, Williams RS. Calcineurin signaling and muscle remodeling. Cell. 2000; 101: 689-692. PMID: 10892739

93. van Rooij E, Sutherland LB, Liu N, Williams AH, McAnally J, Gerard RD, et al. A signature pattern of stress-responsive microRNAs that can evoke cardiac hypertrophy and heart silure. Proc Natl Acad Sci U.S.A. 2006; 103: 18255-18260. PMID: 17108080

94. Ikeda S, Kong SW, Lu J, Bisping E, Zhang H, Allen PD, et al. Altered microRNA expression in human heart disease. Physiol Genomics. 2007; 31(3): 367-373. PMID: 17712037

95. Liu N, Williams AH, Kim Y, McAnally J, Bezprozvannaya S, Sutherland LB, et al. An intragenic MEF2dependent enhancer directs muscle-specific expression of microRNAs 1 and 133. Proc Natl Acad Sci U.S.A. 2007; 104: 20844-20849. PMID: 18093911

96. Tatsuguchi M, Seok HY, Callis TE, Thomson JM, Chen JF, Newman M, et al. Expression of microRNAs is dramatically regulated during cardiomyocyte hypertrophy. J Mol Cell Cardiol. 2007; 42: 1137-1141. PMID: 17498736

97. Sucharov C, Bristow MR, Port JD. miRNA expression in the failing human heart: functional correlates. J Mol Cell Cardiol. 2008; 45(2): 185-192. doi: 10.1016/j.yjmcc.2008.04.014 PMID: 18582896

98. Thum T, Gross C, Fiedler J, Fischer T, Kissler S, Bussen M, et al. MicroRNA-21 contributes to myocardial disease by stimulating MAP kinase signalling in fibroblasts. Nature. 2008; 456(7224): 980984. doi: 10.1038/nature07511 PMID: 19043405

99. Urbich C, Kuehbacher A, Dimmeler S. Role of microRNAs in vascular diseases, inflammation, and angiogenesis. Cardiovasc Res. 2008; 79: 581-588. doi: 10.1093/cvr/cvn156 PMID: 18550634

100. van Rooij E, Sutherland LB, Thatcher JE, DiMaio JM, Naseem RH, Marshall WS, et al. Dysregulation of microRNAs after myocardial infarction reveals a role of miR-29 in cardiac fibrosis. Proc Natl Acad Sci U.S.A. 2008; 105: 13027-13032. doi: 10.1073/pnas.0805038105 PMID: 18723672

101. van Rooij E, Marshall WS, Olson EN. Toward microRNA-based therapeutics for heart disease: the sense in antisepse. Circ Res. 2008; 103: 919-928. doi: 10.1161/CIRCRESAHA.108.183426 PMID: 18948630

102. Catalucci $D$, Gallo $P$, Condorelli $G$. MicroRNAs in cardiovascular biology and heart disease. Circ Cardiovasc Genet. 2009; 2: 402-408. doi: 10.1161/CIRCGENETICS.109.857425 PMID: 20031613

103. Ikeda S, He A, Kong SW, Lu J, Bejar R, Bodyak N, et al. MicroRNA-1 negatively regulates expression of the hypertrophy-associated calmodulin and Mef2a genes. Mol Cell Biol. 2009; 29(8): 2193-2204. doi: 10.1128/MCB.01222-08 PMID: 19188439

104. Ji X, Takahashi R, Hiura Y, Hirokawa G, Fukushima Y, Iwai N. Plasma miR-208 as a biomarker of myocardial Indry. Clin Chem. 2009; 55: 1944-1949. doi: 10.1373/clinchem.2009.125310 PMID: 19696117 
105. Lin Z, Murtaza I, Wang K, Jiao J, Gao J, Li PF. miR-23a functions downstream of NFATc3 to regulace cardiac hypertrophy. Proc Natl Acad Sci U.S.A. 2009; 106: 12103-12108. doi: 10.1073/pnas. 0811371106 PMID: 19574461

106. Rane S, He M, Sayed D, Vashistha H, Malhotra A, Sadoshima J, et al. Downregulation of miR-199a derepresses hypoxia-inducible factor-1alpha and Sirtuin 1 and recapitulates hypoxia preconditioning in cardiac myocytes. Circ Res. 2009; 104(7): 879-886. doi: 10.1161/CIRCRESAHA.108.193102 PMID: 19265035

107. Roy S, Khanna S, Hussain SR, Biswas S, Azad A, Rink C, et al. MicroRNA expression in response to murine myocardial infarction: miR-21 regulates fibroblast metalloprotease-2 via phosphatase and tensin homologue. Cardiovasc Res. 2009; 82: 21-29. doi: 10.1093/cvr/cvp015 PMID: 19147652

108. Adachi T, Nakanishi M, Otsuka Z, Nishimura K, Hirokawa G, Goto Y, et al. Plasma microRNA 499 as a biomarker of acute myocardial infarction. Clin Chem. 2010; 56: 1183-1185. doi: 10.1373/clinchem. 2010.144121 PMID: 20395621

109. Ai J, Zhang R, Li Y, Pu J, Lu Y, Jiao J, et al. Circulating microRNA-1 as a potential novel biomarker for acute myocardial infarction. Biochem Biophys Res Commun. 2010; 391(1): 73-77. doi: 10.1016/j. bbrc.2009.11.005 PMID: 19896465

110. Cheng $\mathrm{Y}$, Tan N, Yang J, Liu X, Cao X, He P, et al. A translational study of circulating cell-free microRNA-1 in acute myocardial infarction. Clin Sci. 2010; 119: 87-95. doi: 10.1042/CS20090645 PMID: 20218970

111. Corsten MF, Dennert R, Jochems S, Kuznetsova T, Devaux Y, Hofstra L, et al. Circulating microRNA208b and microRNA-499 reflect myocardial damage in cardiovascular dinase. Circ Cardiovasc Genet. 2010; 3: 499-506. doi: 10.1161/CIRCGENETICS.110.957415 PMID: 20921333

112. D'Alessandra $Y$, Devanna P, Limana F, Straino S, Di Carlo A, Brambilla PG, et al. Circulating microRNAs are new and sensitive biomarkers of myocardial infarction. Eur Heart J. 2010; 31(22): 27652773. doi: 10.1093/eurheartj/ehq167 PMID: 20534597

113. Fukushima $Y$, Nakanishi $M$, Nonogi $H$, Goto $Y$, Iwai $N$. Assessment of plasma Midas in congestive heart silure. Circ J. 2010; 75: 336-340. PMID: 21157109

114. Song XW, Li Q, Lin L, Wang XC, Li DF, Wang GK, et al. MicroRNAs are dynamically regulated in hypertrophic hearts, and miR-199a is essential for the maintenance of cell size in cardiomyocytes. $J$ Cell Physiol. 2010; 225(2): 437-443. doi: 10.1002/jcp.22217 PMID: 20458739

115. Rane S, He M, Sayed D, Yan L, Vatner D, Abdellatif M. An antagonism between the AKT and betaadrenergic signaling pathways mediated through their reciprocal effects on miR-199a-5p. Cell Signal. 2010; 22: 1054-1062. doi: 10.1016/j.cellsig.2010.02.008 PMID: 20193759

116. Voellenkle C, van Rooij J, Cappuzzello C, Greco S, Arcelli D, Di Vito L, Melillo Get al. MicroRNA signatures in peripheral blood mononuclear cells of chronic heart failure patients. Physiol Genomics. 2010; 42(3): 420-426. doi: 10.1152/physiolgenomics.00211.2009 PMID: 20484156

117. Wang GK, Zhu JQ, Zhang JT, Li Q, Li Y, He J, et al. Circulating microRNA: a novel potential biomarker for early diagnosis of acute myocardial infarction in humans. Eur Heart J. 2010; 31: 659-666. doi: 10. 1093/eurheartj/ehq013 PMID: 20159880

118. Gidlöf $O$, Andersson $P$, van der Pals J, Götberg M, Erlinge D. Cardiospecific microRNA plasma levels correlate with troponin and cardiac function in patients with ST elevation myocardial infarction, are selectively dependent on renal elimination, and can be detected in urine samples. Cardiology. 2011; 118: 217-226. doi: 10.1159/000328869 PMID: 21701171

119. Shieh JT, Huang Y, Gilmore J, Srivastava D. Elevated miR-499 levels blunt the cardiac stress response. PLoS ONE. 2011; 6: e19481. doi: 10.1371/journal.pone.0019481 PMID: 21573063

120. Wang JX, Jiao JQ, Li Q, Long B, Wang K, Liu JP, et al. miR-499 regulates mitochondrial dynamics by targeting calcineurin and dynamin-related protein-1. Nat Med. 2011; 17: 71-78. doi: 10.1038/nm.2282 PMID: 21186368

121. Zile MR, Mehurg SM, Arroyo JE, Stroud RE, Desantis SM, Spinale FG. Relationship between the tempoval profile of plasma microRNA and left ventricular remodeling in patients following myocardial infarction. Circ Cardiovasc Genet. 2011; doi: 10.1161/CIRCGENETICS.111.959841

122. Long G, Wang F, Duan Q, Chen F, Yang S, Gong W, et al. Human circulating microRNA-1 and microRNA-126 as potential novel indicators for acute myocardial infarction. Int J Biol Sci. 2012; 8: 811-818. doi: 10.7150/ijbs.4439 PMID: 22719221

123. Ellis KL, Cameron VA, Troughton RW, Frampton CM, Ellmers LJ, Richards AM. Circulating microRNAs as candidate markers to distinguish heart failure in breathless patients. Eur J Heart Fail. 2013; 15(10): 1138-1147. doi: 10.1093/eurjhf/hft078 PMID: 23696613

124. Wei C, Kim IK, Kumar S, Jayasinghe S, Hong N, Castoldi G, et al. NF-KB mediated miR-26a regulation in cardiac fibrosis. J Cell Physiol. 2013; 228(7): 1433-1442. doi: 10.1002/jcp.24296 PMID: 23254997 
125. Beaumont J, López B, Hermida N, Schroen B, San José G, Heymans S, et al. microRNA-122 downregulation may play a role in severe myocardial fibrosis in human aortic stenosis through TGF- $\beta 1$ upregulation. Clin Sci. 2014; 126(7): 497-506. doi: 10.1042/CS20130538 PMID: 24168656

126. Vyas S, Nicolaides KH, Bower S, Campbell S. (1990) Middle cerebral artery flow velocity waveforms in fetal hypoxaemia. Br J Obstet Gynaecol 1990; 97:797-803. PMID: 2242364

127. Cohn HE, Sacks EJ, Heymann MA, Rudolph AM. (1974) Cardiovascular responses to hypoxemia and acidemia in fetal lambs. Am J Obstet Gynecol 1974; 120:817-824. PMID: 4429091

128. Livak KJ and Schmittgen TD. Analysis of relative gene expression data using real-time quantitative PCR and the 2(-Delta Delta C(T)) Method. Methods. 2001; 25(4): 402-408. PMID: 11846609

129. Vandesomple J, De Preter K, Pattyn F, Poppe B, Van Roy N, De Paepe A, et al. Accurate normalization of real-time quantitative RT-PCR data by geomeztic averaging of multiple internal control genes. Genom Biol. 2002; 3: RESEARCH0034.

130. Andersen C.L., Ledet-Jensen J., Ørntoft T. Normalization of real-time quantitative RT-PCR data: a model based variance estimation approach to identify genes suited for normalization-applied to bladder- and colon-cancer data-sets. Cancer Research. 2004 (64: ): 5245-5250.

131. Bergkvist A, Forootan A, Zoric N, Stromborn L, Sjoback R, Kubista M. Choosing a normalization strategy for RT-PCR. GenEx syste, aids in the selection of reference genes for standardizing mRNA measurements. Genet Eng Biotechnol News. 2008; $28: 13$.

132. Torres A, Torres K, Wdowiak P, Paszkowski T, Maciejewski R. Selection and validation of endogenous controls for microRNA expression studies in endometrioid endometrial cancer tissues. Gynecol Oncol. 2013; 130(3): 588-594. doi: 10.1016/j.ygyno.2013.06.026 PMID: 23811003

133. Dweep $\mathrm{H}$, Sticht $\mathrm{C}$, Pandey $\mathrm{P}$, and Gretz N. miRWalk—database: prediction of possible miRNA binding sites by "walking" the genes of three genomes. J Biomed Inform. 2011; 44(5): 839-847. doi: 10. 1016/j.jbi.2011.05.002 PMID: 21605702

134. Becker $\mathrm{C}$, Hammerle-Fickinger A, Riedmaier I, Pfaffl MW. mRNA and microRNA quality control for RT-qPCR analysis. Methods. 2010; 50(4): 237-243. doi: 10.1016/j.ymeth.2010.01.010 PMID: 20079844

135. Bustin SA. Why the need for qPCR publication guidelines?-The case for MIQE. Methods. 2010; 50 (4): 217-226. doi: 10.1016/j.ymeth.2009.12.006 PMID: 20025972

136. Meyer SU, Pfaffl MW, Ulbrich SE. Normalization strategies for microRNA profiling experiments: a 'normal' way to a hidden layer of complexity? Biotechnol Lett. 2010; 32(12): 1777-1788. doi: 10.1007/ s10529-010-0380-z PMID: 20703800

137. Tricarico C, Pinzani P, Bianchi S, Paglierani M, Distante V, Pazzagli M, et al. Quantitative real-time reverse transcription polymerase chain reaction: normalization to rRNA or single housekeeping genes is inappropriate for human tissue biopsies. Anal Biochem 2002; 309(2):293-300. PMID: 12413463

138. Bas A, Forsberg G, Hammarström S, Hammarström ML. Utility of the housekeeping genes $18 S$ rRNA, beta-actin and glyceraldehyde-3-phosphate-dehydrogenase for normalization in real-time quantitative reverse transcriptase-polymerase chain reaction analysis of gene expression in human T lymphocytes. Scand J Immunol 2004; 59(6):566-73. PMID: 15182252

139. Peltier HJ, Latham GJ. Normalization of microRNA expression levels in quantitative RT-PCR assays: identification of suitable reference RNA targets in normal and cancerous human solid tissues. RNA 2008; 14(5):844-52. doi: 10.1261/rna.939908 PMID: 18375788

140. Suresh K, Chandrashekara S. Sample size estimation and power analysis for clinical research studies. J Hum Reprod Sci 2012; 5(1):7-13. doi: 10.4103/0974-1208.97779 PMID: 22870008

141. Myatt L. Placental adaptive responses and fetal programming. J Physiol 2006; 572:25-30. PMID: 16469781

142. Tappia PS, Gabriel CA. Role of nutrition in the development of the fetal cardiovascular system. Expert Rev Cardiovasc Ther 2006; 4(2):211-25. PMID: 16509817

143. Anderson CM. Preeclampsia: exposing future cardiovascular risk in mothers and their children. J Obstet Gynecol Neonatal Nurs 2007; 36(1):3-8. PMID: 17238941

144. Barker DJ, Osmond C, Golding J, Kuh D, Wadsworth ME. Growth in utero, blood pressure in childhood and adult life, and mortality from cardiovascular disease. BMJ 1989; 298(6673):564-7. PMID: 2495113

145. Barker DJ. The fetal and infant origins of adult disease. BMJ 1990; 301(6761):1111. PMID: 2252919

146. Barker DJ, Bagby SP. Developmental antecedents of cardiovascular disease: a historical perspective. J Am Soc Nephrol 2005; 16(9):2537-44. PMID: 16049070 
147. Hakim J, Senterman MK, Hakim AM. Preeclampsia is a biomarker for vascular disease in both mother and child: the need for a medical alert system. Int J Pediatr 2013; 2013:953150. doi: 10.1155/2013/ 953150 PMID: 23690796 